Authors' Response

\title{
Passive frame theory: A new synthesis
}

(PLEASE DO NOT QUOTE, PROOF)

\author{
Ezequiel Morsella a,b, Christine A. Godwin ${ }^{\mathrm{c}}$, Tiffany K. Jantz ${ }^{\mathrm{d}}$, Stephen C. Krieger ${ }^{\mathrm{e}}$, and \\ Adam Gazzaley, \\ ${ }^{a}$ Department of Psychology, San Francisco State University, San Francisco, CA 94132-4168; \\ ${ }^{\mathrm{b}}$ Department of Neurology, University of California, San Francisco, CA;

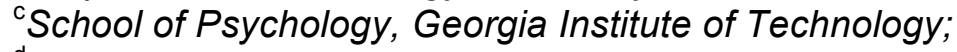 \\ ${ }^{\mathrm{d} D e p a r t m e n t}$ of Psychology, University of Michigan; \\ ${ }^{\mathrm{e}}$ Department of Neurology, Mount Sinai Medical Center; ${ }^{\mathrm{f} D e p a r t m e n t s ~ o f ~ P s y c h i a t r y ~ a n d ~}$ \\ Physiology, University of California, San Francisco, CA. \\ morsella@sfsu.edu
}

\begin{abstract}
Passive frame theory attempts to illuminate what consciousness $i s$, in mechanistic and functional terms; it does not address the "implementation" level of analysis (how neurons instantiate conscious states), an enigma for various disciplines. However, in response to the commentaries, we discuss how our framework provides clues regarding this enigma. In the framework, consciousness is passive albeit essential. Without consciousness, there would not be adaptive skeletomotor action.
\end{abstract}

\section{R1. The nature of the problem and definitions of consciousness}

For decades, the question of what consciousness contributes to the functioning of the nervous system has perplexed theorists and experimentalists, leading some of the greatest scientific minds, including the Nobel laureates Leon Cooper, Francis Crick, Gerald Edelman, Eric Kandel, and Charles Sherrington, to conclude that answering this question is one of the greatest puzzles in science. As Shallice (1972) asserts, "The problem of consciousness occupies an analogous position for cognitive psychology as the problem of language behavior does for behaviorism, namely, an unsolved anomaly within the domain of the approach" (p. 383). Passive frame theory (PFT), a synthesis of diverse ideas, attempts to answer this question and yield novel insights about consciousness and the brain, all within a conceptual framework that, importantly, is internally coherent (Dux, Gainotti) and comprehensive (Mudrik). PFT attempts to illuminate what consciousness contributes to nervous function, how it serves this role, and what consciousness $i s$, at least in mechanistic, functional terms. In the framework, consciousness is passive albeit essential. Without it, there would not be adaptive skeletomotor function. The 
theory does not address what Marr (1982) referred to as the "implementation" level of analysis, that is, how neural activities instantiate these conscious states, which is an enigma for various disciplines, including neurobiology. However, in response to the commentaries, we discuss how PFT provides clues regarding this enigma. In addition, we emphasize how the framework is different from established models.

Regarding the commentaries, we are grateful for their collegial, constructive, and thoughtful nature. We will study these commentaries for years to come. Several of them contain insights (e.g., tasting always requires a voluntary act [Gallo], action selection in dreams [Porte], and unique properties of olfaction [Merker]) that will serve as a basis for future research. Many commentaries also contained deep questions that can be answered only after years of further investigation. We were pleased that many commentators viewed PFT as a unique, novel, and internally coherent framework. Subsequently, we respond to the general themes raised in the commentaries.

With our EASE (elemental, action-based, simple, and evolutionary-based) approach, we focused on the most basic form of consciousness (e.g., the experience of a smell, visual afterimage, tooth pain, or urge to scratch an itch) and contrasted it with unconscious processes (e.g., the pupillary reflex, peristalsis). We avoided precise definitions of the phenomenon under investigation because, as noted by Sir Karl Popper, definition is the final stage, and not the beginning, of scientific inquiry. For scientific progress, one needs only identifications and contrasts (e.g., nausea vs. the pupillary reflex). A useful working definition for basic consciousness is provided by Nagel (1974), who proposed that an organism possesses basic consciousness if there is something it is like to be that organism - something it is like, for example, to be human and experience pain, breathlessness, or yellow afterimages. Similarly, Block (1995) proposes, "The phenomenally conscious aspect of a state is what it is like to be in that state" (p. 227). All the contents of which one is conscious compose the conscious field, which changes over time (Fig. 1). The size of the field changes, in a sense, when a new content, which could stem from polysensory configurations of afference (e.g., the McGurk effect), becomes conscious (Fig. 2). 


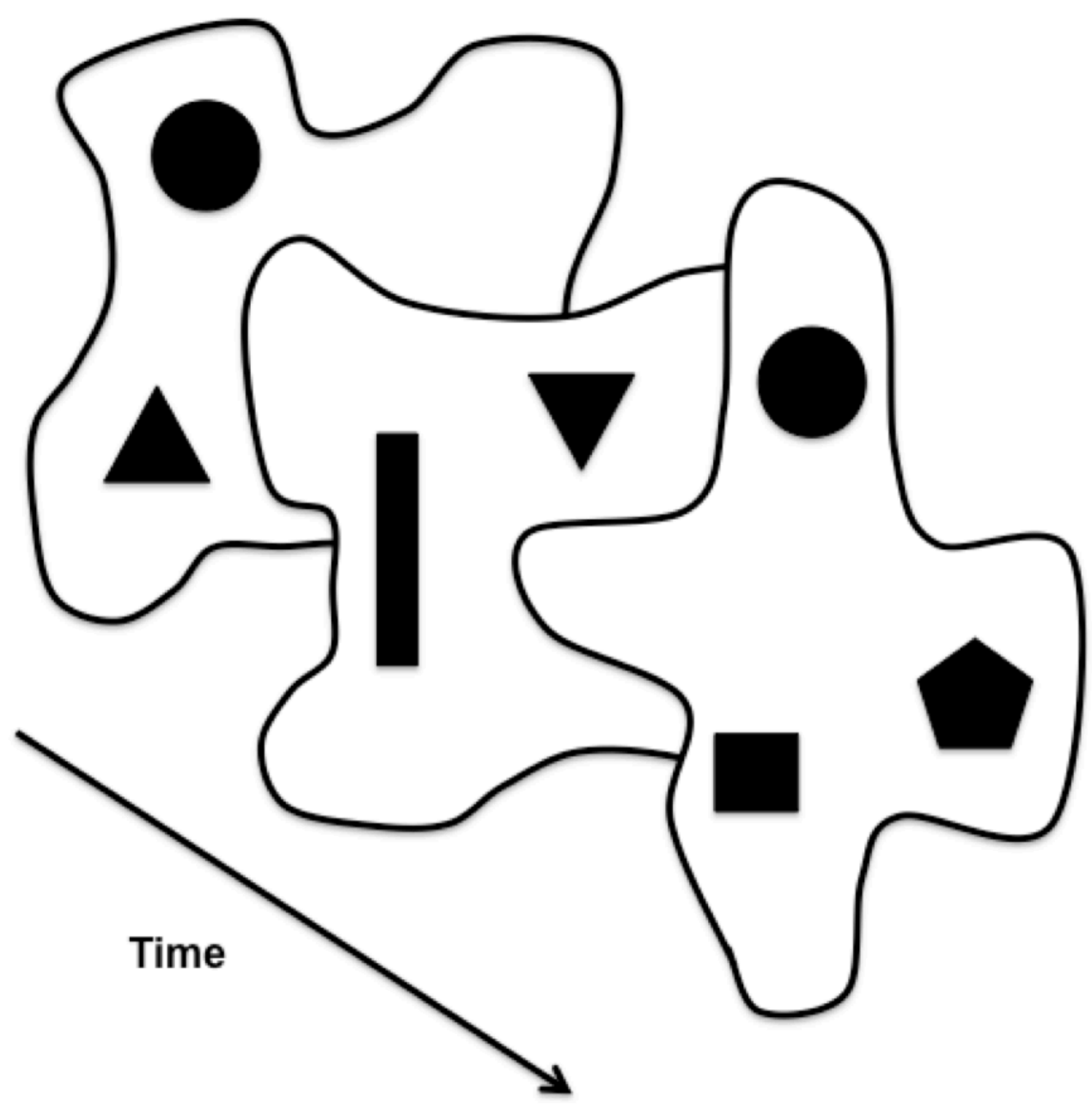

Figure 1. The conscious field, with a different medley of conscious contents at each moment in time. Each of the three conscious fields, representing three different moments in time, possesses its own configuration of conscious contents (the filled shapes). One conscious content (e.g., the triangle) can be a sound; another conscious content (e.g., the square) can be an olfactory stimulus or an action-related urge.

\section{R2. Explanatory power and novelty of passive frame theory}

Blackmore, Lin, Mudrik, and Prinz requested clarifications about the explanatory power of PFT. As a synthesis of six theoretical approaches from diverse fields of study (ideomotor theory, subset consensus, integration consensus, encapsulation, sensorium hypothesis, and PRISM [parallel responses into skeletal muscle]), PFT yields novel insights. For example, our approach specifies how, when these hypotheses are united, then something resembling our proposed "frame" architecture (in which the skeletomotor response to one conscious content is framed by the other contents) would be required for adaptive action. PFT also explains subjective data from (a) intersensory conflicts, (b) smooth muscle conflicts (Morsella et al. 2009a), (c) synchrony 
blindness (sect. R7), and (d) skeletomotor conflicts (e.g., holding one's breath). PFT also explains (e) why one is conscious of contents even when those contents are irrelevant to other contents or to ongoing action, and, relevant to Seth's comment regarding the relationship between consciousness and effector systems, (f) why skeletal muscle is the only "voluntary" muscle. Regarding (f), it is important to emphasize that the conscious acts of expressing (or suppressing) inhaling, blinking, swallowing, and micturating all involve, specifically, skeletal muscle. Accordingly, regarding digestion, one is conscious only of those phases of the process that require coordination with skeletomotor plans (e.g., chewing or micturating) and none of those that do not (e.g., peristalsis). Conversely, no skeletomotor plans are involved in the actions of consciously impenetrable processes such as the pupillary reflex, peristalsis, and stomach action, all of which involve smooth muscle. ${ }^{1}$ Hence, in response to Seth, the integration achieved through conscious processing is intimately related, not to perceptual processing, smooth muscle control, or motor control, but to skeletomotor action selection. Simply put, PFT explains that consciousness is for voluntary action. Without conscious mediation, adaptive integration fails to occur, as in the case of unintegrated actions (e.g., dropping a hot dish or failing to hold one's breath while underwater).

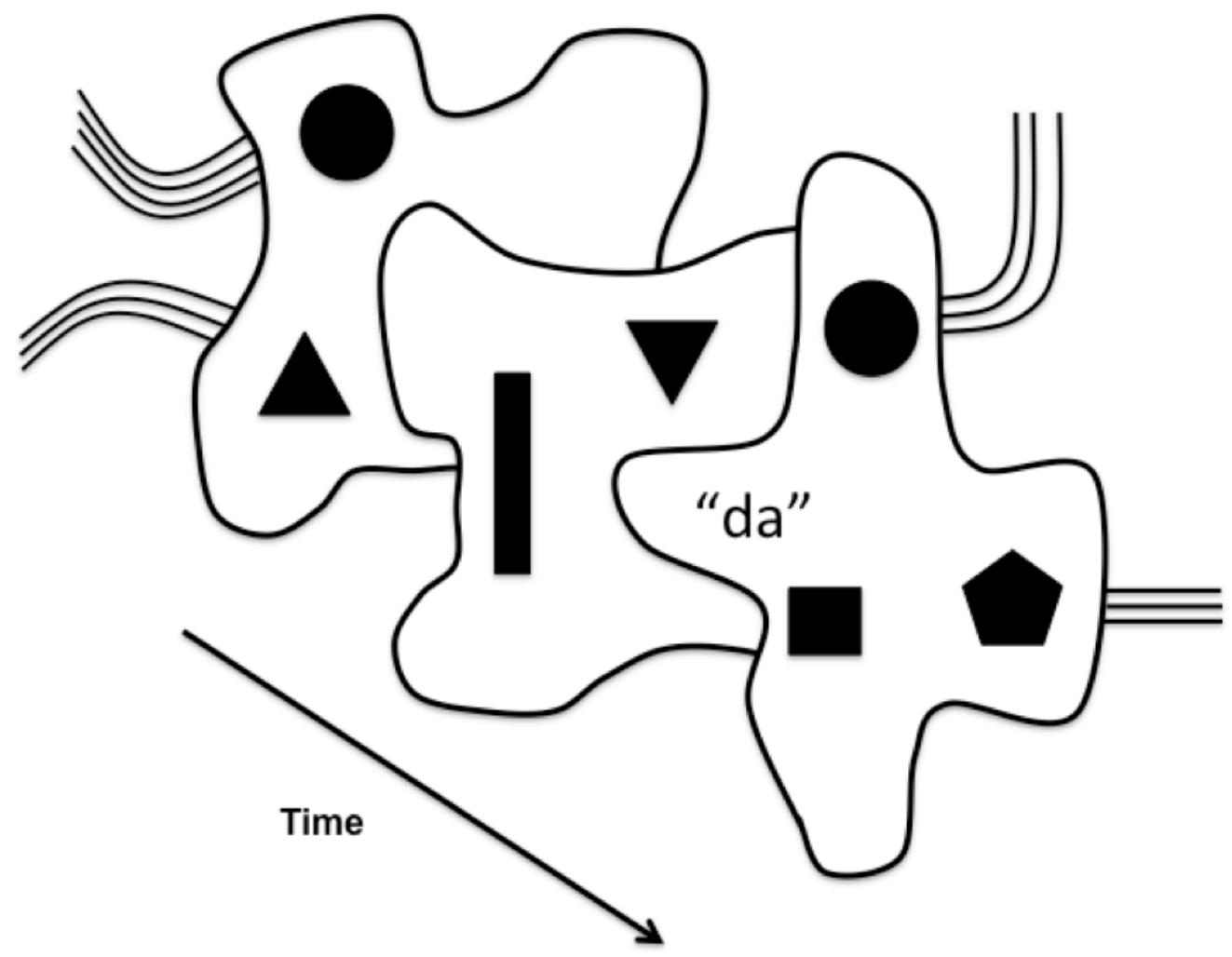

Figure 2. The conscious field, with a different medley of conscious contents (filled shapes) at each moment in time. The conscious field during the third moment includes the percept "da," induced by the intersensory, McGurk illusion. Another conscious content could be a phonological representation (e.g., /haus/) triggered by seeing a word (e.g., "HOUSE"). The lines feeding into each conscious field represent the unconscious and often polysensory configurations of afference that are involved in the generation of each content. 
Many commentators mentioned that the approach is novel. Others (e.g., Blackmore, Hommel \& Wiers) requested more information regarding its novelty. (As a synthesis, PFT naturally contains ideas that have been presented elsewhere.) First, unlike other approaches, PFT specifies which integrations require consciousness and which do not, which is a current and major problem (cf. Mudrik et al. 2014). Several approaches posit that the integration associated with consciousness is for high-level semantic processes (Mudrik et al. 2014; Thagard \& Stewart 2014), which is at odds with our more "low-level," action-based proposal. There are also accounts in which consciousness is, not for intra-organismic processes, but for high-level, sociocultural interactions (Banks 1995; Carlson 1994; Frith 2010; Macphail 1998; Prinz 2012). Other high-level accounts (e.g., Clark 2002; Koch 2004) propose that conscious processes are functionally unique because they tax semantic memory or top-down processes or are capable of anticipating the future. Moreover, some have hypothesized that consciousness serves no function in action control (Hommel 2013; Koch 2014; Masicampo \& Baumeister 2013; see also Jackson 1986; Kinsbourne 1996; 2000; Pinker 1997). (Here we are excluding mention of the many theories in which consciousness is epiphenomenal.) As is evident in the commentaries, some theorists (e.g., Blackmore) disagree with our basic assumptions that there is a difference between conscious and unconscious processing and that consciousness is associated with only a subset of nervous function.

Second, unlike other approaches, we propose that the integration provided by consciousness is associated, not with perceptual processing (e.g., afference binding), efference binding, or smooth muscle binding, but with binding for a peculiar kind of action control. Third, PFT is unique in specifying that conscious contents influence only action systems and not content generators: Conscious contents are sampled only by action systems. As far as we know, PFT, building on Morsella (2005) and Merker (2013), is the only such account. PFT is also unique in that it focuses on olfaction instead of on vision and is action based instead of perception based.

Moreover, PFT is unique in proposing that (a) conscious contents cannot influence each other either at the same time or across time, which counters the everyday notion that one conscious thought can lead to another conscious thought; (b) one conscious content does not "know," and should not know, of its relevance to ongoing action, to higher-order goals, or to other contents in the field; (c) though consciousness is not epiphenomenal or omnipresent (e.g., as in panpsychism), its role is more passive and less teleological than that of other accounts (e.g., Baars 1988; 2002; Dehaene 2014); (d) during a frame check, the field functions as a unitary entity in terms of its influence over the skeletomotor output system, an important point that renders moot the debate concerning whether the conscious field should be construed as a unitary or componential entity (cf. Searle 2000): Action-related modules in the skeletomotor output system must treat, in terms of functional consequences, the mosaic of contents in the field as one thing. Last, (e) PFT reveals that, during action selection, anticipated action effects, actual action effects, and information about the immediate environment must exist as comparable tokens in a common decision space. Although consciousness has historically been associated with the highest levels of processing, here it is revealed that consciousness must occur at the level of processing that is shared with that of representations of the immediate external environment (e.g., olfactory stimuli). The conscious field is concerned most not about the future or past, but about 
the immediate present (Pahlavan \& Arouss), the scenario in which overt action will unfold. Last-minute changes in a course of action might arise from entry of new contents (Merker 2013).

Hommel \& Wiers requested that we differentiate PFT from "global workspace" approaches. Consistent with Baars (1988; 2002; see similar models in Anderson 1983; Minsky 1985; Selfridge 1959), PFT proposes that these states integrate nervous processes that are otherwise independent. However, PFT is based more on Jamesian ideomotor approaches, which are action based, than it is on workspace models. In the development of PFT, that which rendered it internally coherent was reconciling ideomotor theory with encapsulation: If one adopts the notions of encapsulation and of ideomotor processing, in which percepts must activate response codes (which also occurs in "continuous flow" [McClelland 1979] or "cascade" [Eriksen \& Schultz 1979] models), and if one accepts that intuitions about perception and action (as in the case of a blackboard diagram in which sensory inputs are connected to motor outputs) are actually computationally impossible (Tsotsos $1995 ; 2011)$, then it becomes apparent that something like our proposed frame is needed for adaptive action. Unlike the workspace models (e.g., Baars 1988; Dehaene 2014), which propose that conscious representations are broadcast to modules engaged in both stimulus interpretation and content generation, in PFT (as in Merker 2007), the contents of the conscious field are directed only at the unconscious processes of the skeletomotor output system (Fig. 3). The proposed architecture is consistent with the view (Cisek 2007; Cisek \& Kalaska 2010) that, in the nervous system, actional processes cannot be distinguished from decision-making processes (see Hardcastle, White, Kloos, \& Hardcastle [Hardcastle et al.]). Last, unlike in workspace approaches, in which consciousness serves more than a handful of functions (e.g., Baars 1988; Dehaene 2014), we propose that the conscious field serves only one basic, passive role. It performs this same basic function for several kinds of processes, including some high-level functions (e.g., in adult humans). Figuratively speaking, in PFT, the real work is not done in the conscious field (Gur): The conscious field is a workspace without the work (Lashley 1956). In contrast, according to Baars (1988), consciousness serves many functions, including adaptation and learning, decision making, analogy forming, editing and debugging, metacognitive self-monitoring, and autoprogramming. 


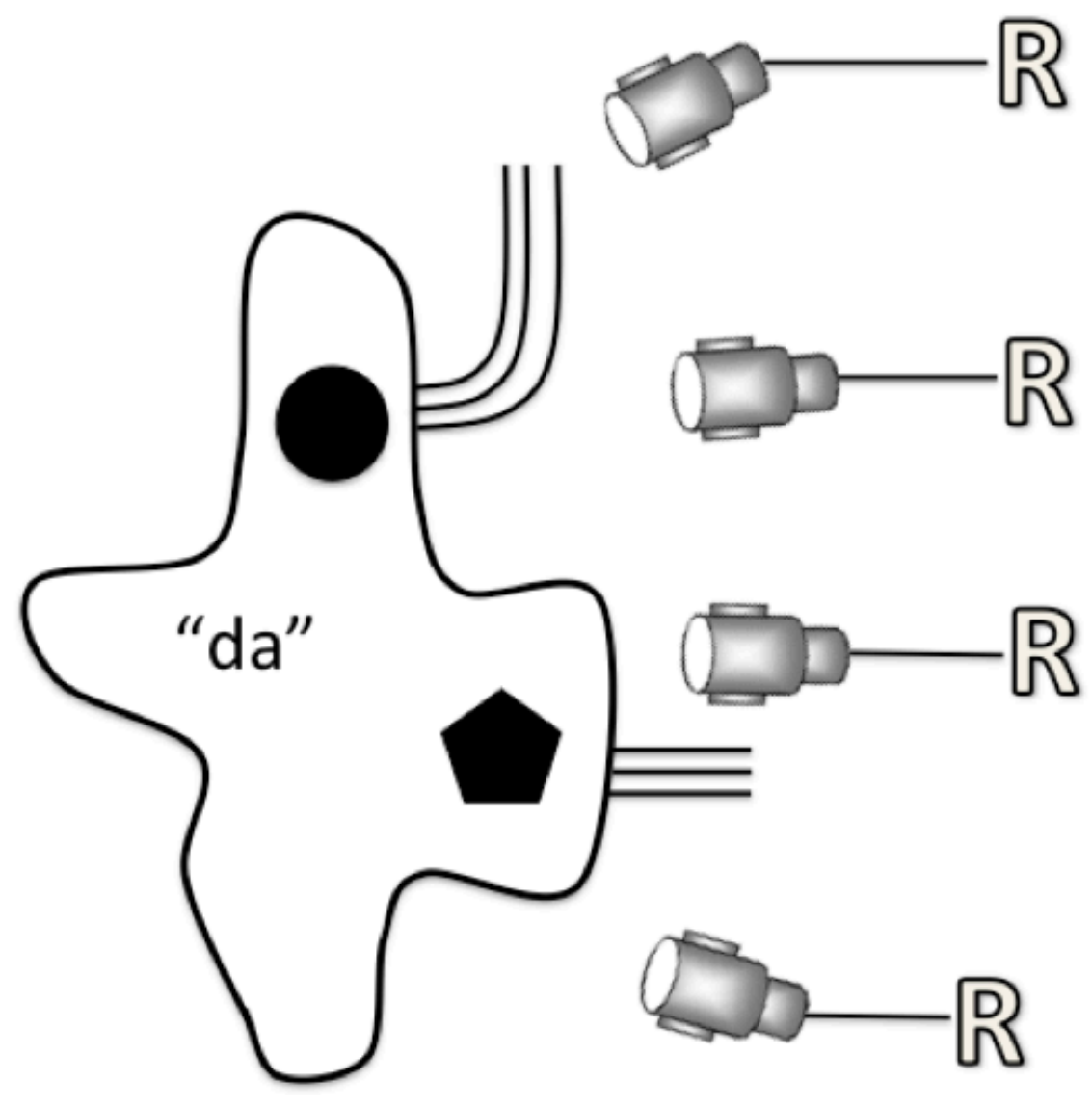

Figure 3. At one moment in time, the conscious contents are apprehended by the unconscious, action mechanisms of the skeletal muscle output system. Each mechanism (represented by a gray sensor) is associated with a certain kind of (unconsciously mediated) action (e.g., articulating vs. reaching), which is signified by the $R$ s (for Responses).

\section{R2.1. Field construction and conscious versus unconscious integrations}

In PFT, both the content generators and response systems are complex, unconscious processes, which is consistent with comments (Lin, Mudrik) about the sophistication of unconscious processes. It is clear that, in the construction of the conscious field, there is the participation of unconscious representations from both bottom-up and top-down sources, including those associated with frontal cortex (Bar et al. 2006; Perlovsky). As noted by Perlovsky and by LeDoux (1996), some of these pre-conscious representations are "vague" and poorly developed compared to conscious contents (Perlovsky). The mechanisms of multiple drafts (Dennett 1991), apperception (Wundt 1902/1904), and reentrant processing involve unconscious afference from top-down and bottom-up sources (Bar et al. 2006; Basso, Dux, Perlovsky, Porte). These processes illuminate how the contents in the conscious field could satisfy the criteria of multiple modules, a form of multiple-constraint satisfaction (Dennett 1991; Merker 2012) yielding the 
"global best estimate" of what each content should be (Helmholtz 1856/1961; Merker 2012). Although these mechanisms explain the underpinnings of good field construction, they do not account for the first-person perspective or subjectivity.

Related to Blackmore, Gur, Mudrik, and Lin's comments about conscious versus unconscious integrations, the latter can occur for perceptual (e.g., intersensory) processing, smooth muscle control, motor programming, and stimulus-response reflexes. Unconscious integrations also occur in the perception of the flavor of food, which involves the combining of information from multiple modalities (including haptic, gustatory, and olfactory; Shepherd 2006), and in pain perception, in which there is, for example, interaction between sensory (lateral pain system) and affective (medial pain system) components (Melzack \& Casey 1968; Nagasako et al. 2003). Evidence reveals that, even for high-level executive processing, much of what transpires is actually unconscious (Dehaene 2014; Suhler \& Churchland 2009), as in the case of determining tendencies (Ach, 1905/1951). In response to Mudrik's comment about the conscious penetrability of perception, it is important to reiterate that rivalrous percepts (e.g., the Necker cube or binocular rivalry) or intersensory illusions (e.g., the McGurk effect) are resolved unconsciously: At one moment, consciousness is occupied by only one unambiguous interpretation of the stimulus (Merker 2012). One is conscious only of the outcome of any competitive processes. Hence, for an experimental subject, the McGurk effect "just happens" in much the same manner as does dream content (Lin, Porte). The only conflicts that one is conscious of are associated with action selection.

We agree with Basso, Franz, Gur, Lin, Mudrik, Pahlavan \& Arouss, and Schwartz \& Pournaghdali that the conscious field affords a type of processing in which the behavioral response to a given content (e.g., a stimulus eliciting aggression or the McGurk effect) is modulated (or "framed") by the other contents (e.g., smoke) composing the field (Fig. 2). Accordingly, as Lin notes, responding adaptively to a complex array of stimuli (e.g., a visual scene) requires consciousness. The conscious field permits downstream, motor-related processes to respond to a stimulus in a manner that is contextually sensitive. This kind of sensitivity appears to be unlike anything we find in the robots of today. In short, the conscious field solves the problem, in behaviorism, of the complex discriminative stimulus.

This sensitivity has led some to conclude that the conscious field is for flexible responding (Basso, Franz, Gur, Lin, Mudrik, Pahlavan \& Arouss, Schwartz \&

Pournaghdali). PFT is in accord with proposals in which consciousness affords what appears to be a flexible, multi-determined response (Crick \& Koch 2000; Searle 2000; Sergent \& Dehaene 2004). However, it should be clarified that consciousness, over time, seems to be more flexible than it is. PFT reveals that the same contents will always yield the same voluntary action, with the combination of contents wholly and exclusively determining voluntary action selection. Consider that, if one experienced half of what is normally the whole conscious field, though behavior would certainly suffer, one would not notice the absence of information independent of a content generated by a system dedicated to detecting such discrepancies. In this way, confusion and other forms of metacognition are not givens. (Similarly, the perception of time and spatial "perspective," whether in the first-person perspective or third-person perspective, are not givens [Einstein \& Infeld 1938. Instead, they are mental creations that are experimentally manipulable; Ehrsson 2007].) These contents are generated by devoted systems that constrain action selection, 
as Schwartz \& Pournaghdali note. In the conscious field, there is often the absence of information but not information about absence (Bridgeman, personal communication, April, 16, 2014; Simons \& Levin 1997). Accordingly, and related to Hommel \& Wiers's insights about addiction, urges in the field can be short lived but have, in the absence of strong tendencies against them, a strong influence on behavior (Loewenstein 1996).

Faced with the apparent flexibility of consciousness, one might propose that the function of consciousness is one of instantiating stimulus-response relationships that are "arbitrary." One problem with this hypothesis is that (a) it is difficult to define what constitutes an arbitrary mapping between perception and action; (b) there are countless cases of unconscious processes that seem to involve arbitrary mappings, as in the case of motor programming (Grossberg 1999; Rosenbaum 2002); and (c) some non-arbitrary mappings (e.g., holding one's breath yields a negative subjective state) never become unconscious, despite extensive training and rehearsing of the perception-to-action mappings (Poehlman et al. 2012). Moreover, unlike PFT, this hypothesis fails to explain why smooth muscle actions and intersensory conflicts are always mediated unconsciously.

\section{R3. The focus on simple cases: Low-level versus high-level conscious contents}

To investigate the primary function of consciousness, we were influenced by how progress was achieved in the field of physics (Einstein \& Infeld 1938). Hence, we focused on simple cases and low-level phenomena (e.g., percepts and urges). Regarding urges, in our creature in the cave scenario, the noxious stimulus leading to an inborn avoidance tendency could have been, instead of smoke, some other odorant (e.g., hydrogen sulfide eliciting an inborn disposition of disgust; Gallo, Gur, Lathe, Mudrik). Our point was to illustrate that the inborn action tendency toward the smell changed the manner in which the creature responded to perceptual features of the scene (e.g., the opening) that were already represented in the conscious field. In response to Gur's comments about the capabilities of our creature in the cave, we should emphasize that we interpreted as parsimoniously as possible the operations giving rise to the behavior of this creature, a creature that is not as hypothetical as we thought (D'Souza \& Bremner).

Regarding the ubiquitous distinction between high- and low-level conscious contents (de Vries \& Ward; Dux; Franz; Gur; Hardcastle et al.; Hommel \& Wiers; Jordan \& Vinson; Melo, Koscik, Vrantsidis, Hathaway \& Cunningham [Melo et al.]; Mudrik; Perlovsky; Swain, Caluser, Mahmood, Meldrim \& Morelen [Swain et al.]; Vonasch, Masicampo, \& Baumeister [Vonasch et al.]), one contribution of our action-based approach is that these distinctions are unnecessary. In PFT, all of these different kinds of contents can be construed as tokens which, through the conscious field, constrain voluntary action. From this standpoint, a percept, urge, nausea, and even a high-level sense, such as the sense of agency (which is experimentally manipulable [Riddle et al. 2015] and was touched upon by Gur, Massaro \& Rowe, Mudrik, Pahlavan \& Arouss, Prinz, and Schwartz \& Pournaghdali), are just contents in the conscious field that constrain action selection. For example, while driving, a tip-of-thetongue state concerning important information could influence action selection (e.g., one decides to park in order to concentrate on retrieval; cf. Schwartz \& Pournaghdali). Hence, a percept, urge, and even a metacognition are similar in terms of their functional consequences. From this standpoint, a primitive form of self is necessary, not for the instantiation of consciousness (as in Prinz 2012; Prinz), but rather for adaptive action selection. 
In addition, for adaptive action, the highest of conscious contents must be married, in a sense, to the representational format of the lowest and phylogenetically oldest contents: Highlevel contents must exist in the same decision space and share the representational format with contents as primitive as those of olfaction. Hence, knowledge of the most primitive systems involved in the conscious field will reveal much about the nature of the highest systems, such as those of concern to Dux and Vonasch et al. As de Vries \& Ward note, the latter are constrained by the former, which might be the most tractable to investigate. This is consistent with Shepherd's (2007) conclusion that "the basic architecture of the neural basis of consciousness in mammals, including primates, should be sought in the olfactory system, with adaptations for the other sensory pathways reflecting their relative importance in the different species" (p. 93). In humans, skeletomotor action conflicts often include a medley of high- and low-level contents. ${ }^{3}$ This is evident when, faced with a yellow traffic light, one decides to begin to brake or to speed up (it depends on context; see Woodman \& Vogel 2005, p. 111). It is also evident in Merker's "burnt broccoli" example and in the following scenario: "I am hungry and desire steak, but I am Catholic, and it is Good Friday." Our "Thanksgiving dinner" example was intended to demonstrate how a high-level function - language - must take into account contents from a phylogenetically older function - that is, olfaction. Consistent with Melo et al., Schwartz \& Pournaghdali, and Merker, the high-level contents (including metacognitions and emotion) participate with the low-level contents in the constraining of action selection. Accordingly, Freeman (2004) proposes that conscious representations of different sensory origins must at some level be similar in form in order for them to be integrated into a polysensory gestalt of the world. The format must permit interaction between perceptual and motor systems (Freeman 2004) if there is to be perception-to-action translations (Prinz 2003).

In agreement with Vonasch et al., much can be learned from what has been regarded as high-level contents (e.g., our insights about the McGurk effect and subvocalization, Helmholtz's [1856/1961] insights about automatic reading). The focus on simpler aspects of human behavior reflects only the presently intended scope of PFT. It is hoped that, after empirical and theoretical developments, the model will generalize to more complex phenomena, including aggression (Pahlavan \& Arouss), taste (Gallo, Lathe), development (D'Souza \& Bremner), emotion (Gainotti, Melo et al., Pahlavan \& Arouss), addiction-related behaviors (Hommel \& Wiers), dream consciousness (Porte), and parental consciousness (Swain et al.). The commentators have illuminated the under-explored action-related aspects of these phenomena. Emotional phenomena, with their action-related components (Melo et al.; Frijda 1986), provide a rich domain in which to develop PFT (Gallo, Gainotti, Melo et al., Pahlavan \& Arouss). (As Gainotti notes, affective neuroscience provides additional evidence for a cortical account of consciousness [see also Dux].) Concerning human development (D’Souza \& Bremner, Swain et al.), we were delighted to learn that our creature in the cave may not exist only hypothetically. Such insights from the commentators will help test and extend PFT. In addition, our aim is to eventually unify PFT, already a synthesis, with frameworks concerning ecological perception (de Vries \& Ward), attention (e.g., the allocation of attention to action model of Franz), emotion (e.g., the iterative reprocessing model of Melo et al.), and chaos and complexity (Hardcastle et al.).

Regarding the generation of high-level contents, it is important to reiterate that, when 
discussing unconscious inference, Helmholtz (1856/1961) was referring not only to the unconscious generation of low-level contents, but also to the generation of high-level contents (e.g., automatic word reading; Augustinova \& Ferrand 2014). In many cases, high-level contents (e.g., subvocalizations) "just happen" as do low-level contents (e.g., nausea; Porte; see also reflex-like activations of high-level contents in Haidt [2001] and Tetlock [2002]). To investigate how such high-level contents can arise in consciousness unintentionally and in a reflex-like manner, we developed the reflexive imagery task (RIT; Allen et al. 2013). In this paradigm, the insuppressible conscious contents are from high-level processes, including involuntary object counting (Merrick et al. 2015), subvocalizations, and even the kind of word transformations in the childhood game of Pig Latin (Cho et al. 2015). The more we learn from the RIT about the generation of high-level contents, the more this generative process resembles that of low-level contents.

From the standpoint of PFT and in response to Massaro \& Rowe, Mudrik, Perlovsky, Schwartz \& Pournaghdali, and Seth, the outputs from a "narratorium" or an "interpreter" module that draws coherent (albeit often incorrect) conclusions about the current context (Roser \& Gazzaniga 2004) are just another kind of content, produced by dedicated systems that participate in the conscious field. Consciousness, which is passive, does not reason or draw conclusions. Instead, systems devoted to reasoning or to drawing certain kinds of conclusions (e.g., about a puzzle or a piece of music) have their outputs represented in the conscious field, just as a modular system can maintain an undesired "earworm" in consciousness.

PFT provides a similar answer regarding memory. We agree that many memorial processes are consciously impenetrable (Schwartz \& Pournaghdali) and that the activities of content generators are influenced by past experiences. Memory is essential for the adaptive generation of, and response to, contents (Basso, D'Souza \& Bremner, Gur, Hardcastle et al., Hommel \& Wiers, Jordan \& Vinson, and Lathe). However, these processes stem from dedicated systems operating outside the conscious field, which itself has no memory. (This is evident in neurological conditions.) Similarly, anticipatory processing (Jordan \& Vinson, Seth), which is essential for perception and other forms of content generation, occurs outside the conscious field, which is not burdened with the operations of memory, prospection, or deliberation (Hardcastle et al.). (Relevant to the experimental findings by Hardcastle et al., which involved dissociations between perception and action, expressed actions could sometimes influence not perception, but only the memory of the expressed action [Cooper et al. 2012].)

\section{R3.1. Metacognition and consciousness across the phyla}

Compared to all the functions that have been proposed to be the primary function of conscious processing, the proposed function of consciousness in PFT is the most basic and primitive one. In response to Rosenbaum's point about animal consciousness, PFT, when further developed, might serve as a tractable framework with which to investigate consciousness in animals. However, at this stage of understanding, it is premature to apply our framework to other animals. Across the phyla, it is the case that the same function (e.g., locating an object) can be carried out by vastly different mechanisms (e.g., vision vs. echolocation). Hence, one cannot conclude that a given action (e.g., holding of breath) in species $X$ is carried out by the same mechanisms by which it is carried out in species $Y$. Even within one species, the same function could be carried out by more than one mechanism (Dawkins 1982). Hence, before making cross-species 
comparisons, which are problematic, science must explain the perplexing contrasts within selfreporting, adult humans. (This conclusion is relevant also to idea of extending PFT to infants; D'Souza \& Bremner.) At present, in humans alone there are sufficient contrasts (e.g., the pupillary reflex vs. conscious pain) that are difficult to explain. (In addition, as Swain et al. note, the most basic of human functions - as simple and primitive as they have been deemed to be nonetheless seem to occupy much of the brain's activity and to dominate much of human existence, especially during the most critical of periods [e.g., early childhood, parenting].)

Nevertheless, it is worth reiterating that, because our approach is simplistic and evolutionary based, it may be the most suitable framework to be extended to the study of other animals. Insofar as one would like to study consciousness across species, one should focus on olfaction, for several reasons, including that it is the most phylogenetically preserved modality and a "common denominator" region of the vertebrate brain. Moreover, when conducting experiments on adult humans, it is much easier to induce olfactory percepts than high-level, metacognitive states and background states, such as those mentioned by Basso, de Vries \& Ward, Franz, Perlovsky, and Schwartz \& Pournaghdali. For example, regarding tip-of-thetongue states and feelings of knowing, it is difficult to control exactly when these states arise, and little is known about their neural correlates. At this stage of understanding, it is progressive to focus on obvious, easily reportable forms of conscious content (e.g., detecting a smell) and not on more nebulous conscious states (e.g., background states). The lack of verbal report regarding the stimulation of frontal areas may indeed reflect the greater difficulty of communicating about these contents than about perceptual events. Hence, in the current version of PFT, we limit ourselves to the kinds of conscious contents occurring in our creature in the cave scenario. Nevertheless, these high-level states, which involve the frontal cortex, may provide unique insights regarding consciousness.

Franz questioned whether olfaction is a model system for consciousness research. Justifications for our focus on olfaction can be found in the target article (Note 1 and sect. 3.5). We are grateful for Merker's listing of additional properties of olfaction (e.g., minimal spatialization, habituability of ordinary odorants, innate preferences, pheromonal signaling) that render it a good modality for investigating consciousness. As Gallo notes, other unique properties of olfaction are that there is no such thing as a "neutral" odorant and that swallowing is almost always a voluntary act. Concerning habituation (Merker), this phenomenon occurs in a special manner for olfaction because of the absence of the possibility of voluntary re-access to an exposed odorant (Merker; Stevenson 2009). Regarding the "experiential nothingness" associated with habituation, research indicates that (a) activation in the orbitofrontal cortex does not decrease over odorant exposure (60 seconds; Poellinger et al. 2001), and (b) accurate odor detection persists after activation in the piriform cortex decreases to a baseline (or below baseline) level (Poellinger et al. 2001; Sobel et al. 2000). When isolating the neural correlates of olfactory consciousness, one should seek regions that are active most during conscious detection but not during habituation or subliminal perception (Merrick et al. 2014). Merker's forwardlooking insights also reveal that much can be learned about olfactory consciousness by examining the activities of cortical layer VI pyramidal cells and the effects on olfactory consciousness from perturbations (e.g., lesions) of the dorsal pulvinar, a multimodal region whose activity is tightly linked with conscious perception (Wilke et al. 2009).

\section{R4. Passive frame theory explains the primary function of consciousness}


Prinz astutely questions whether PFT provides a functional account of consciousness. (Prinz also requested a definition of subjective experience that is distinct from our functional account of consciousness. This definition is provided in sect. R1.) We agree that a constellation of isolated facts (e.g., that skeletal muscle but not smooth muscle can be consciously controlled) does not constitute by itself an explanatory model, just as one can know that the sun rises every morning and that the seasons change without having an explanatory model of the solar system. Hence, it is one thing to know that skeletal muscle can be consciously controlled, but it is an entirely different matter to have an explanatory framework that integrates such a fact into a coherent, causal account. PFT provides such a framework.

Perhaps this issue is better illustrated by analogy. In naively observing the digestive system, one could generate hypotheses concerning the circumstances under which, say, salivary amylase is secreted into the mouth. However, these hypotheses would be fundamentally different from those regarding the primary function of salivary amylase, which would have to propose, in addition, what it is for (e.g., digestion of starch in the mouth) and, by extension, what phenomena would occur to a lesser degree without it. As a theory about function, PFT supersedes these criteria by claiming that (a) consciousness is necessary for collective influence over the skeletomotor output system, (b) no other process performs this role, and, (c) without these states, collective influence and integrated actions would be absent. Except for the fact that the actions of salivary amylase upon starch can be observed directly (e.g., in a Petri dish), the functional claims about this enzyme and consciousness are analogous.

Then, of course, there are questions regarding how salivary amylase breaks down starches and why salivary amylase, and not some other substance, was selected in evolution to carry out this function. With respect to biological systems, how and why questions are fundamentally different from what for questions (Lorenz 1963; Simpson 1949). PFT explains what consciousness is for, that is, the nature of its primary function. How physical processes carry out collective influence is a variant of the "hard problem" and is hence outside the scope of PFT. In addition, one must distinguish the primary role of evolutionary adaptations from their secondary

roles (Dawkins 1982; Gould 1977; Lorenz 1963). A scientist could argue, for example, that color perception evolved for selecting fruits and detecting camouflaged prey, but no one doubts that color perception could also be used to appreciate a painting. The color harmony of a painting is perceptible to us because it involves the kinds of stimuli that are of adaptive significance in other contexts. In response to Prinz, we perceive the kinds of things that we evolved to act upon (Dawkins 1982; LeDoux 2012). As humans, we have inherited the conscious field. Like the eye, it has a fixed architecture, one that, though having a net adaptive effect across all the stages of ontogeny, may not function adaptively in all contexts. Its adaptive value may not be evident in one particular situation (e.g., when experiencing unhealthy urges).

\section{R4.1. The conscious field does not require conflict or skeletal muscle}

In response to comments about the liaison between conflict and consciousness (D'Souza \& Bremner, de Vries \& Ward, Gur, Hardcastle et al., Hommel \& Wiers, Lathe, and Massaro 
\& Rowe), in PFT, a content does not require conflict to enter the conscious field, which is a "continuous feed" system. The conscious field is not for conflict monitoring per se, but rather for collective influence, which is especially important under conditions of conflict. (We agree with Jordan \& Vinson that people underestimate how many action conflicts occur on a given day.) In PFT, contents, because of the requirement of encapsulation, do not know about the nature of other contents nor about whether there is conflict. In addition, the contents do not know whether they are relevant for ongoing action. The notion that no conscious content can directly influence another conscious content, either at the same time or across time, is consistent with gestalt theory (e.g., Werner and Kaplan's [1963] notion of dynamic schematization) and with Helmholtz's (1856/1961) "global perception," in which unconscious configurations of afference interact to generate an unambiguous conscious field, which can be construed as a static mosaic of conscious contents. As Merker (2013) notes, the kinds of sensorial interactions involved in illusions (the McGurk effect), color constancy phenomena, and other perceptual phenomena occur not in the conscious field, but in the (unconscious) processing of afference, occurring before the construction of the conscious field. For example, though a content such as the McGurk effect is influenced by different kinds of configurations of afference, once the content is conscious, it cannot be modified on the basis of other contents. In PFT, the contents are not there to communicate with each other.

Concerning Rosenbaum's question about animals lacking skeletal muscle, in PFT, there is nothing intrinsically special about skeletal muscle that causes it to be related to consciousness. Skeletal muscle is one of many "multi-determined" effectors in the body. (Consider that the pupillary reflex, involving smooth muscle, too, is multi-determined, as it is influenced by light conditions, emotions, and other variables.) Conscious processes are distinguished from unconscious ones not simply because they "involve" skeletal muscle, but because they involve skeletal muscle in a particular manner, in which encapsulated systems (having different operating principles and phylogenetic origins) vie to express their respective skeletomotor plans.

Pertinent to Rosenbaum's question, one can also ask, If conscious states are primarily for skeletomotor action, then why do they persist even when the skeletomotor system is deactivated because of, for example, neural damage? In response to this criticism, one should consider the following analogy. Many of today's automobiles contain navigational systems whose primary function is to aid navigation. With this in mind, it is conceivable that the navigational system would continue to function despite problems with, say, the transmission of the car. Similarly, conscious processes, whose primary function is serving skeletomotor action, can continue to function after the peripheral structures that they are intended to serve are nonoperational. (Similar decoupling of central conscious processing from peripheral events occurs in phantom limb [Ramachandran 1999].)

\section{R5. Attention, automaticity, and the timescale of consciousness}

In response to the concerns of Basso, Dux, Lin, and Franz about the relationship between attention and consciousness (see differing about this relationship in Koch and Tsuchiya [2007] and Cohen et al. [2012]), we posit that the nature of this relationship depends in large part on one's definition of attention. As noted by Tsotsos (2011), there are more than a handful of 
definitions of attention. Most theorists construe attention as a cause, something that influences information processing in a certain way, whereas other theorists, interestingly, construe it as an effect, for example, as a by-product of a value-based selection process centered on the basal ganglia (Krauzlis et al. 2014). In addition, for Oberauer and Hein (2012), there is a low-level form of attention, having certain properties, and a separate, higher-level form of attention, having other properties. It could be argued that one of these forms of attention, but not the other, is somehow necessary for basic consciousness. From our standpoint, it has to be explained how attention, defined one way or another, is necessary for the detection of basic conscious contents such as nausea or a gas leak (see related Merker comment about olfactory attention).

We next turn to the topic of automaticity, which was raised by Gur, Massaro \& Rowe, and Rosenbaum. Regarding the contrast between novel actions (e.g., the first time one ties one shoes) and automatized actions (e.g., the ten thousandth time one ties one's shoes), it is difficult to ascertain which aspects of consciousness, if any, are diminished in the latter. In making such a contrast, one could easily conflate changes in consciousness and the well-known changes in attentional processes that stem from automaticity (Baars 1997; Logan et al. 1999; Puttemans et al. 2005). The question is, What would be no longer consciously accessible when driving home automatically? One benefit of PFT is that when contrasting conscious and unconscious processes, the contrast is between processes of which one is never conscious (e.g., the pupillary reflex and peristalsis) and processes of which one is almost always conscious (e.g., pain and air hunger while holding one's breath).

In response to Hommel \& Wiers's thoughtful question about the timescale at which consciousness operates (related to Massaro \& Rowe), we should state that according to PFT, the timescale must be that associated with normal, ongoing voluntary action selection, which is different for different kinds of voluntary acts (e.g., taking a deep breath vs. looking left to right) and is often slower than that of reflexive actions. Whatever the exact timescale in humans (or in other species; de Vries \& Ward), it must be slow enough for the frame check to include the relevant contents for the adaptive employment of a given effector and quick enough (on the order of hundreds of milliseconds) to benefit actions occurring at fast rates (e.g., voluntary saccades). Regarding the former, it is interesting to consider that the instruction to a subject to press a button whenever there is a noticeable change in any part of the sensorium requires the action processes associated with that effector to, in a sense, sample a wide variety of contents in a very short time.

\section{R6. Evolution, functionalism, and emotion}

Prinz and others (Massaro \& Rowe, Mudrik) question why the function attributed to consciousness is not solved unconsciously, as are many other functions. After all, it is easy to imagine integrated actions (e.g., suppressing inhalation) occurring without anything like a conscious field. However, there are many hypothetical solutions to phylogenetic challenges that the human body did not arrive at by way of evolution. In our descriptive account, intuitions regarding how the nervous system should work take a back seat to actual data revealing the manner in which it actually works. Hence, it seems premature to adopt an epiphenomenal stance 
(e.g., Blackmore) until there is a sufficient scientific understanding about the place of consciousness in nature. We should add two comments. First, our intuitions of how nervous systems should function, in which sensory inputs are connected to motor outputs, are actually computationally impossible (Tsotsos 1995; 2011). (Regarding this issue, Neal Miller [1959] hypothesized that "central states" could provide a solution to the problem [see discussion in Corr \& Morsella 2015].) Second, some of the counterintuitive adaptations in evolutionary history (e.g., intra-psychic conflict) are actually good solutions given the hardware at hand (e.g., slow processing units; Livnat \& Pippenger 2006).

One could also ask, If consciousness is for action selection, then why is one aware of so many things that do not demand immediate action (e.g., the plot of a story; Basso, de Vries \& Ward, Gur, Perlovsky, Porte)? One could certainly imagine more efficient systems - and more falsifiable models - that invoke the conscious field only under conditions when it is needed most (e.g., conflicting action tendencies). The apparent inefficiency of the field is an incontrovertible, first-person property of these states. In the absence of any conflict or obvious demands upon action, one is continuously conscious of, say, a red object standing before one. This counterintuitive property of the field can be likened to the efficiency of the continuously running conveyor belt of the ball-return machine at a bowling alley (Morsella 2005), which is inefficient in the sense that it constantly expends energy, even when there are no bowling balls needing to be returned to players. However, the machine is more efficient than a machine having an additional mechanism that determines whether a ball needs to be returned. Such deceptively "inefficient" solutions can be observed in physiology outside the nervous system, as in biological filters (e.g., the kidneys), which continuously filter a substrate regardless of the status of the substrate. Just as eyes do not turn off when there is nothing interesting to look at, the conscious field does not turn off when its role is unneeded.

Regarding one's consciousness of a story that may never influence behavior, it should be stated that simulacra such as novels have been constructed to incite attentional, emotional, and other kinds of processes for only an infinitesimally recent fraction of human history. Consistent with PFT, the stimuli from simulacra succeed in part because they activate inflexible, encapsulated systems that, at some level, are incapable of "knowing" that what is occurring is not "real." (Consistent with this view is the idea that emotional systems [e.g., for fear and aggression] evolved independently and are modularized in the brain [LeDoux 2000; 2012; Öhman \& Mineka 2001].) Scary movies, for example, are capable of activating to some degree the kinds of affect associated with the natural observations of the portrayed events. For the majority of our natural history, such activation was clearly adaptive. Though such inclinations and imagery operate in a realm shielded from that of expressed action, they are still intimately related to action. (Relevant to Porte, in certain neurological conditions, sleep paralysis fails and patients act out their dreams, revealing the intimate link between conscious content and action. Sleep paralysis is mediated by inhibition only at the latest stages of motor control [e.g., at the spinal level; Glenn \& Dement 1981].) Thorndike (1905) concludes, "The function of thoughts and feelings is to influence actions ... Thought aims at knowledge, but with the final aim of using the knowledge to guide action" (p. 111).

Prinz asks how the design of consciousness, a product of evolution, reflects the needs of adaptive action control. First, we subscribe to the uncommon position that consciousness is best 
understood by examining the requirements of adaptive efferent action control rather than the needs of perceptual analysis. ${ }^{4}$ Accordingly, as noted by Merker (2013), the conscious field is organized egocentrically (see Prinz 2007), around an active agent that reaches, locomotes, and performs other acts that are spatially directed. This organization is found also in the dream world (Porte). (PFT pertains to normal waking consciousness, but as noted by Porte, the kind of action selection occurring in dreams seems isomorphic to that of waking.) For action selection, it would be disadvantageous for this first-person arrangement to break down and for an object on the left to be represented as if on the right. According to PFT, the first-person perspective and other properties of the field (e.g., its having varied elements) result from the demands of adaptive action selection. Second, the valence and other properties of a conscious content are in some ways isomorphic to ongoing action. It is not the case, for example, that pleasant states are associated with avoidant behaviors or that unpleasant ones are associated with approach behaviors. (As noted by James [1890], this non-arbitrary relationship between valence and action poses a problem for epiphenomenalism.) Similarly, as Sperry (1952) notes, and consistent with de Vries \& Ward's discussion of affordances, perceptual contents (e.g., the shape of a triangle) are often more isomorphic with action plans (e.g., tracing) than with sensory inputs (the proximal stimulus on the retina). In conclusion, much of the way the field is designed, including a primitive sense of self (the first-person perspective), reflects the demands of adaptive action selection.

\section{R7. Integrated ("voluntary") action and subliminal stimuli}

The evidence for PFT is the combined evidence for each of the hypotheses composing the framework. For such a synthesis, which attempts to account for so many disparate observations, there will naturally be both evidence for and against each of its constituent hypotheses. For example, there are bits of empirical evidence that, at first glance, appear to challenge the hypotheses of encapsulation and ideomotor processing and that consciousness is dependent on cortical processes. In the coming years, the evidence for and against the tenets composing PFT should be examined carefully. Some of the tenets of PFT will be amended; others will be abandoned.

Nevertheless, today there is substantially more evidence in favor of PFT than there is against it. Moreover, much of the evidence supporting PFT can be obtained not just in the laboratory, but in everyday scenarios (e.g., the unawareness of peristalsis and the pupillary reflex vs. the subjective experience of holding one's breath). These bits of evidence, realized in everyday life scenarios and not dependent on the technicalities of the laboratory, are often the most compelling forms of evidence. PFT focuses on modal findings (i.e., the most common findings) regarding when conflicts are conscious and when they are not. At this stage of the scientific understanding of a problem as thorny as consciousness in the brain, the mode is very informative.

Ayars mentions the well-known finding in which a prime (e.g., a rightward arrow) is presented subliminally before a target stimulus (e.g., a leftward arrow) to which the subject must respond. In this paradigm, the response to the target is modulated by the prior presentation of the prime. For example, interference (e.g., increased response latencies) is less when the two arrows match (the congruent condition) than when they mismatch (the incongruent condition; Eimer \& Schlaghecken 2003; Schlaghecken et al. 2006). Similarly, the subliminal presentation of the 
image of a spider could, in principle, ramp down an appetitive, behavioral "approach" system. The data mentioned by Ayars are corroborated and complemented by many similar findings (e.g., Hughes et al. 2009; Van Opstal et al. 2010), some of which stem from our own laboratory, in which subliminal stimuli induced behavioral inclinations that induced subjective urges and also influenced behavior, even though subjects were unaware of the source of these urges (discussed subsequently and in Morsella et al. 2011). Accordingly, Desender et al. (2014), after reviewing the literature on subliminally induced inhibition in interference paradigms, conclude, "The difference between awareness of a prime and experience of a conflict is of crucial importance ... Response conflict might give participants the general feeling that something is wrong, without their knowing why or what is wrong" (p. 681). To Desender et al. (2014), this subjective experience of conflict, regardless of awareness of the prime, is essential for the top-down control of behavior.

The effect described by Ayars could arise from various mechanisms (Logan et al. 2015; Munakata et al. 2011), including negative priming (Tipper 1985) or the residual effects from the prime having activated, through unconscious efference binding, a response code (consistent with sect. 3.2 of the target article) that does not match the subsequently activated response code. (In sect. 3.2, we also discuss the relevant fact that motor programs, which are unconscious, are modulated in sophisticated ways by external stimuli.) We agree that past experience can influence the activities of content generators and response systems (discussed subsequently). For example, a response code is likely to function more quickly when it was activated recently (repetition priming) than when it was not activated recently.

Second, and more important, we should clarify that collective influence from a frame check pertains to a class of phenomena (e.g., holding one's breath while underwater or suppressing some other, prepotent and simultaneously activated action plan) that is fundamentally different from the kind of established, sequential priming effect described by Ayars, in which a prime modulates (but does not fully suppress) a subsequent behavior. As noted by Morsella and Bargh (2011, p. 341):

The level of activation of the plans involved in integrated action is far beyond that of "sub-threshold" activations. For example, in psycholinguistic research, there is substantial evidence that naming "dog" primes the action plan for naming a member of the same category (e.g., "horse"; Levelt, 1989). The level of activation that we are speaking of in our definition of integrated action is far above this threshold - it is at the level of activation at which action plans would not only influence overt action but trigger action.

They also state that "integrated action occurs when two (or more) action plans that could normally influence behavior on their own (when existing at that level of activation) are simultaneously co-activated and trying to influence the same skeletal muscle effector" (Morsella $\&$ Bargh 2011, p. 341). These actions occur when one holds one's breath, refrains from dropping a hot dish, suppresses the urge to scratch an itch, or makes oneself breathe faster for some reward (Morsella 2005; Morsella et al. 2009a). These are discrete, goal-directed actions (e.g., carrying an object, depressing a lever), behaviors Skinner (1953) characterized as operants (pp. 14-15). Based on ideomotor theory (e.g., Harleß 1861; James 1890), PFT proposes that the conscious 
contents associated with behavioral control are action outcomes in the world (e.g., a button depressed) or the body (e.g., fingers snapping). This addresses the second question by Rosenbaum.

Before returning to the experimental effect mentioned by Ayars, we should add that, through collective influence, the field permits for a massive many-to-one (or, at least, many-tofew) conversion (Merker 2013), for there are many action-related contents but only a few operants that, at one time, direct behavior. This may reflect the mechanical limitations of the skeletomotor system, in which only one word can be uttered at a time (Wundt 1900), or, more precisely, in which only one (or a few) operant can be expressed at one time. As noted by Rosenbaum, this aspect of PFT should eventually be integrated with research on the psychological refractory period (Pashler 1993; Welford 1952), which, though not directly concerning conscious processing, yields conclusions that are consonant with PFT. Pashler (1993, p. 52) concludes:

The limitations in carrying out stimulus-response tasks concurrently are not introduced at the level of stimulus perception, nor in production of the motor response. Those mental operations can work in parallel. Rather, the problem is in deciding what the response will be, and this kind of mental operation seems to be carried out in series - that is, one task at a time.

One of our aims is to first integrate PFT with this important research (along with research on the role of action control on attention; e.g., Allport 1989; Neumann 1987) and then isolate, within the architecture of PFT, the locus of the action selection bottleneck. For now, PFT is consistent with Jackendoff's (1990) view that consciousness reflects some form of intermediate, actionplanning stage in between sensory and motor processing. More specifically, we propose that consciousness is associated with stages that, though clearly subsequent to those of sensory processing (Hochberg 1998; Logothetis \& Schall 1989; Marcel 1993), precede those of action selection. It seems that one is unaware of the computational products of action conflicts, resolutions that, should they exist (see Kaufman et al. 2015), determine the general course of observed action (pressing one button instead of another). Consciousness reflects action options, both those that are selected and unselected.

The co-activation of action plans in integrated action can be indexed by behavioral and neural measures, as there are several behavioral and neural features that could be used to distinguish integrated from unintegrated action. For example, like any behavior of low strength, conflicted action (a form of integrated action) is easier to perturb than un-conflicted or unintegrated action (Skinner 1953). Unlike the conscious field, overt behavior is "integrated" in the sense that only one discrete operant is manifest (Lin), even though behavior is influenced by two action plans, as in the case of the Stroop incongruent condition. Unlike in the experimental effect described by Ayars, collective influence permits for one operant to be expressed, leading to only one effect in the world (e.g., a button pressed), while another operant is (almost) fully suppressed, leading to no noticeable effects in the world. ${ }^{5}$ Interestingly, the suppressed operant in a conflict could be the prepotent plan, as in the case of holding one's breath. (Investigators have begun to examine the behavioral consequences of such unselected plans [Filevich \& Haggard 2013].) With this in mind, we can respond to Jordan \& Vinson's insightful point challenging 
the distinction between perception and action. First, in natural selection, it is overt behavior and not musings and mentations that are directly selected. The latter, along with mental simulations, are, in a sense, less costly than is overt behavior. Importantly, behavioral inclinations can often be behaviorally suppressed but not mentally suppressed (Bargh \& Morsella 2008). Second, the distinction between perception and action is an informative one because motor control, unlike perception, is largely unconsciously mediated. This is one of many differences between perception and action.

Relevant to the critiques by Blackmore, Lin, Mudrik, and Prinz about the explanatory power of PFT, the framework reveals that, unlike involuntary actions (e.g., dropping a hot dish because of the pain-withdrawal reflex), voluntary actions can be construed as a form of integrated action. Hence, PFT defines voluntary action in ways more informative than the common "homuncular" definition of these acts - that an action is voluntary if the organism intended to do it. As noted by Passingham (1995), voluntary actions are special in that they can be suppressed; from the present standpoint, the act of suppression (suppressing a cough) is an archetypal integrated action. Again, this act is different from many forms of inhibition in the nervous system, many of which are unconscious, as in the case of lateral inhibition and negative priming. (Relevant to Ayars, PFT does not state that inhibition requires consciousness.) One might then argue that, instead of proposing a framework such as PFT, it is more parsimonious to hypothesize that the role of consciousness is to suppress actions, for holding one's breath or performing response interference tasks (e.g., the Stroop task) involves response suppression. However, this fails to account for the role of consciousness in integrated actions such as breathing faster for some reward, which requires collective influence but no suppression.

Regarding subliminal stimuli, we agree that these controversial stimuli can influence subsequent behavior in one way or another (see review in Morsella \& Bargh 2011). (Consistent with the conclusions of Lin, some have argued that subjects do perceive these stimuli but that, for some reason [e.g., confabulation or distortions of memory], subjects fail to report about the conscious percept [Block 2007].) Moreover, unlike many, we do believe that these controversial stimuli can be regarded as unconscious. Interestingly, in some cases, the subject can be unconscious of the stimulus but be aware of the skeletomotor urges engendered by them (Morsella et al. 2011), which is consistent with the idea that one can be aware of skeletomotor inclinations (e.g., urges) but be unaware of the sources of these inclinations, as in many of the cases mentioned by Lathe and Seth and as found in research from our laboratory (Morsella et al. 2011) and in the classic research by Nisbett and Wilson (1977), in which participants were unaware of the factors influencing their decisions (e.g., to aid a stranger). Hence, people can be conscious of tendencies (e.g., urges and cravings), but not necessarily of the factors engendering the tendencies (Baker et al. 2004; Nisbett \& Wilson 1977). For example, the subjects in Nisbett and Wilson's experiments were certainly aware of their "urge" to, say, help a stranger who had collapsed. If the subjects had been physically unable to aid the stranger because the stranger was in a precarious environment, then subjects would have certainly reported that, though they suppressed helping behavior, they nonetheless experienced the urge to help. This inclination would be conscious even though the factors giving rise to it would be unconscious. PFT predicts that the operating principles within content generators (e.g., for urges) can be opaque to awareness, as in the unconscious factors that engender addiction-related urges (Baker et al. 2004). Accordingly, research has shown that people can have inexplicable "gut feelings" (or 
"somatic markers"; cf. Damasio et al. 1991) reflecting the response tendencies of systems whose inner workings and learning histories are opaque to awareness (LeDoux 2000; Öhman \& Mineka 2001; Olsson \& Phelps 2004). In short, the source of a response tendency is distinct from the awareness of that inclination.

Hence, in the kind of experiment mentioned by Ayars, subjects might be unaware of the stimuli but be aware of the skeletomotor urges triggered by such stimuli. (Desender et al. [2014] conclude that such awareness is required to counteract the interference effects from response conflict induced by subliminal or supraliminal stimuli.) We have found such effects with subliminal stimuli (discussed in Morsella et al. 2011) but have found it challenging to prove unequivocally that the stimuli were unconscious (cf. Lin). In the kind of experiment described by Ayars, one must examine not only whether subjects are unaware of the stimuli and, should they exist, the stimulus-elicited urges, but also that the contrast between the two conditions is not driven solely by a facilitatory effect from the congruent condition.

We should add that subliminal stimuli are problematic also because they are stimuli of very weak strength, unlike the kind of stimuli on which unconscious processes usually operate (Bargh \& Morsella 2008). Hence, in several studies (e.g., Molapour et al. 2011; Morsella et al. 2009a; 2009b), we induced action-related urges by the presentation of supraliminal distractor stimuli in paradigms such as the Stroop and flanker tasks. Consistent with Nisbett and Wilson (1977), it is unclear whether subjects were aware of the source of these urges (see discussion in Morsella et al. 2009b). For example, though the urges arising from different flanker conditions were systematic (Morsella et al. 2009b), it seemed that subjects were unaware of why urges differed across conditions. To further investigate how action-related conscious contents can be triggered systematically and unintentionally by supraliminal stimuli, we developed the aforementioned RIT. With this paradigm, one can examine how unconscious processes operate over supraliminal stimuli. According to the traditions of Freud and Helmholtz, this is the usual way in which unconscious processes operate.

The conclusions on which PFT is based do not stem from controversial techniques such as visual masking (see Lin). Again, much of the evidence supporting PFT can be obtained in everyday scenarios. Regarding laboratory data, of the many conditions in interference paradigms, the strongest perturbations in consciousness (e.g., urges to err) are found in conditions involving the activation of incompatible skeletomotor plans (Morsella et al. 2009a; 2009b), such as in the incongruent Stroop condition or the response interference (vs. perceptual interference) condition of the flanker task (see quantitative review of evidence in Morsella et al. [2011]). Conversely, when distinct processes lead to harmonious action plans, as when a congruent Stroop stimulus activates harmonious word-reading and color-naming plans (e.g., BLUE in blue font), there are little such perturbations in consciousness, and participants may even be unaware that more than one plan influenced overt action (e.g., uttering "blue"). This phenomenon, called synchrony blindness (Molapour et al. 2011), is perhaps more striking in the congruent ("pro-saccade") condition of the anti-saccade task (Hallett 1978), in which distinct brain regions/processes indicate that the eyes should move in the same direction (cf. Morsella et al. 2012). Regarding the Stroop congruent condition, MacLeod and MacDonald (2000), after carefully reviewing the behavioral and psychophysiological data, conclude, "The experimenter (perhaps the participant as well) cannot discriminate which dimension gave rise to the response on a given congruent trial" 
(p. 386). Last, as mentioned in Note 8 of the target article, experiments have revealed that, in simpler tasks, incompatible skeletomotor intentions (e.g., to point right and left) do produce systematic intrusions into consciousness, but, as predicted by PFT, no such changes accompany smooth muscle conflicts or conflicts occurring at perceptual stages of processing (e.g., intersensory processing; Morsella et al. 2011).

We are in agreement with Bridgeman that there are many perceptual events that are unconscious, as in the case of backward masking, saccadic suppression, change blindness, and changes in self-generated action that are below the just noticeable difference for proprioception (Jeannerod 2006). (The eye, discussed by Bridgeman, is interesting because it includes all the kinds of actions contrasted in PFT: smooth muscle action [for pupillary reflex], involuntary skeletomotor action [e.g., a blink], and voluntary skeletomotor action [e.g., a wink].) PFT proposes not that all perceptual processes are conscious, but that motor control is unconscious and that, for the little that is conscious in the perception-to-action cycle, it is associated with the former. In short, one is trapped in the sensorium, but, even within it, one is not conscious of everything. Consistent with PFT, that which one is conscious of regarding eye movements consists of the kinds of things that are important for adaptive action selection. Seeing the world as unstable or the blurring of the retinal image would not serve this end.

According to Ayars, D’Souza \& Bremner, Keller, and Schwartz \& Pournaghdali, PFT is too restrictive in proposing that the integrative role of consciousness is only for the skeletomotor output system. (For example, Seth astutely recommends that we extend PFT to include effects upon the autonomic nervous system.) We believe that, first, our restriction renders the framework more falsifiable and fecund, and, second, the majority of the strongest bits of evidence corroborates it. Figuratively speaking, and in response to Lin, people tend not to experience conflict-related perturbations in consciousness while experiencing the McGurk, ventriloquist effect, or conflict in the pupillary reflex (Morsella et al. 2009a), but such is not the case while people perform the Stroop task or exert self-control (Baumeister \& Vohs 2004; Preston \& Wegner 2009), all of which involve skeletomotor conflict. Regarding the related, important insights by Keller, PFT is consistent with the notion that something represented in the conscious field may incidentally, because of the unconscious afference with which the content is necessarily coupled (e.g., the sensory inputs in the McGurk effect), be linked with effects other than those upon skeletomotor action. For example, in indirect cognitive control, which is germane to the sailing boat analogy by Hommel \& Wiers, adult humans often rely on such effects. A process such as salivation, noted by Keller, could be controlled voluntarily only in such a sophisticated manner. Consistent with PFT, because conflicts involving salivation (or the pupillary reflex) do not involve the skeletomotor output system, one is oblivious about their existence.

Regarding the scope of PFT, it is worth noting that, regarding the role of consciousness, PFT is less restrictive than Godwin et al. (2013), who propose that consciousness is tool used by not all sub-systems in the skeletomotor output system, but only what has been construed as the instrumental response system (Bindra 1974; 1978; Morsella 2005; Tolman 1948). Moreover, PFT does not go as far as Morsella (2005) in limiting the abilities of unconscious processes (e.g., in limiting the amount of unconscious "cross talk" between systems). However, PFT portrays 
consciousness as more passive than what is proposed by Morsella (2005).

\section{R8. Clues from PFT regarding the neural correlates of consciousness}

Even though PFT is not about the neural mechanisms giving rise to consciousness, which is Marr's implementation level of analysis, the framework provides new clues regarding the matter and does rule out certain possibilities (e.g., panpsychism). Hence, though PFT does not attempt to solve the hard problem, it does restrict potential candidate explanations.

One benefit of the architecture outlined in PFT is that, for it, the puzzle of the mind-body problem is the same whether (a) the tokens (conscious contents) differ from each other qualitatively or quantitatively, (b) there is one or many tokens (the former might be more theoretically tractable), or (c) the field is unitary or componential. The first is important because we know that the brain can implement quantitative codes. For example, it has been proposed that consciousness depends on "precise synchronization of oscillatory neuronal responses in the high frequency range (beta, gamma)" (Singer 2011, p. 43). Uhlhaas et al. (2009) specify that the earliest signature of conscious processing is "the precise phase locking across a widely distributed cortical network" (p. 11). Singer (2011) adds that "brain states compatible with conscious processing should be characterized by a high degree of synchrony" (p. 43). Similar conclusions about the role of high frequencies (e.g., $>30 \mathrm{~Hz}$ ) in consciousness can be found in other projects (Aru \& Bachmann 2009; Crick \& Koch 1990; Doesburg et al. 2005; 2009; Engel \& Singer 2001; Hameroff 2010; Jung-Beeman et al. 2004; Meador et al. 2002;

Panagiotaropoulos et al. 2012; Uhlhass et al. 2009; Wessel et al. 2012). More generally, it has been proposed that, to instantiate consciousness of any kind, the mode of interaction among regions (interregional synchrony) is as important as the nature and loci of the regions activated (Buzsáki 2006; Fries 2005; Hummel \& Gerloff 2005; Lewis et al. 2012; Ward 2003).

There is less consensus regarding how, to instantiate the conscious field, high-frequency bands such as gamma (gamma in the rat, ranging from $40 \mathrm{~Hz}$ to $100 \mathrm{~Hz}$; Adrian 1942; Kay \& Beshel 2010) must interact with ongoing, lower-frequency bands. It appears that these interactions between frequency bands are complex and dynamic. In addition, controversy continues regarding which brain regions are primarily responsible for the high-frequency brain rhythms linked to consciousness and whether cortical electroencephalography reflects consciousness (Merker 2012).

Olfaction provides a portal for understanding the neural correlates of "additions" to the conscious field. (Olfaction was one of the first systems in which the nature of oscillatory activity in the brain was investigated [e.g., Adrian 1942].) Olfactory information may be encoded through oscillating neural assemblies (Adrian 1942; 1950a; 1950b; Eeckman \& Freeman 1990; Freeman 1975; Kim et al. 2006; Laurent \& Davidowitz 1994). Different odorants elicit different patterns across spatially distributed neural ensembles of the olfactory bulb (Freeman 1987; Laurent \& Davidowitz 1994; Xu et al. 2000).

In our creature in the cave example, the smell of smoke is an addition to the conscious field that influences skeletomotor responses toward other conscious contents (e.g., the percept of the opening). Examining the neural correlates of such an addition reveals more evidence for the integration consensus. ${ }^{6}$ In olfaction, it is frequencies in the beta range $(\sim 15-30 \mathrm{~Hz}$ in the rat; Kay 
\& Beshel 2010; Kay et al. 2009) that link olfactory processing to non-sensory, cognitive areas (Vanderwolf \& Zibrowski 2001; Zibrowski \& Vanderwolf 1997). Specifically, beta oscillations in the olfactory bulb "entrain" both areas of the piriform cortex, suggesting that beta oscillations may serve the purpose of transmitting olfactory information from the olfactory bulb to higherorder, more cognitive areas, including cortical and subcortical areas. Accordingly, research outside of olfaction has found that beta may be involved in large-scale coupling for sensorimotor integration (Freeman 2007; Siegel et al. 2012). In addition, Kay et al. (2009) propose that "beta oscillations are associated with motor models, favoring this oscillation as a good substrate for long-distance communication" (p. 7). Accordingly, beta coherence between the olfactory bulb and the hippocampus accompanies odor learning in a go/no-go task (Martin et al. 2007). (See Lathe's treatment about olfaction and the hippocampus.) It has been proposed that, though the higher frequency of gamma (in the rat, $40-100 \mathrm{~Hz}$; Kay \& Beshel 2010) can be observed in processing at primary sensory areas, when the sensory information becomes part of a wider network that includes activations from other sensory modalities, then the frequencies are in the beta range (Freeman 2007). (Mechanisms engendering gamma during odor perception reside within the olfactory bulb [Freeman 1979].) Based in part on such neural evidence, it has been hypothesized that one becomes conscious of an olfactory percept only when the representation is part of a wider network involving other systems (Cooney \& Gazzaniga 2003), such as motor (Mainland \& Sobel 2006) or semantic-linguistic (Herz 2003) systems. Accordingly, sensory research outside of olfaction has found evidence that beta may be involved in sensory gating (Hong et al. 2008) or in large-scale coupling for sensori-motor integration (Siegel et al. 2012).

Importantly, unlike gamma oscillations, oscillations in the beta range require participation of (at least) the piriform cortex (Neville \& Haberly 2003). (If the lateral olfactory tract is disrupted, gamma oscillations in the bulb persist [Gray \& Skinner 1988].) The higher the task demand (e.g., fine discrimination vs. simple discrimination), the higher the gamma amplitude will be in early perceptual processing (Beshel et al. 2007; Stopfer et al. 1997). Accordingly, disturbing gamma oscillations in invertebrates impairs the discrimination of similar odors (a high task demand) but does not impair the discrimination of dissimilar odors (a low task demand; Stopfer et al. 1997).

Importantly, appreciation of the long-studied oscillatory properties of the olfactory system corroborates what has been observed in other sensory modalities (cf., Fries 2005; Sauseng \& Klimesch 2008; Siegel et al. 2012; Singer 2011): (a) the synchronizations of high frequencies (e.g., gamma) in local (e.g., olfactory bulb) afferent processing (Bruns \& Eckhorn 2004; Kay \& Beshel 2010; von Stein \& Sarnthein 2000), especially when the process is challenging (e.g., fine discrimination vs. simple discrimination; Kay \& Beshel 2010), and (b) the synchronization at a somewhat slower frequency range (e.g., beta or theta) for integration with a larger-scale cognitive network (Kay et al. 2009; Key \& Beshel 2010). (For a review of the neural correlates of olfactory consciousness, see Merrick et al. [2014].)

The foregoing reveals some conceptual progress regarding the neural correlates of consciousness. As noted by Merker, it is clear that isolating the neural correlates of olfactory consciousness will require further investigation. (It should be reiterated that, for good reasons, some have claimed that cortical electroencephalography does not reflect conscious processing [Merker 2013].) Critical for the study of the neural correlates of consciousness, and for the 
cortical-subcortical controversy, is Merker's insight about the necessary role of the dorsal pulvinar in olfactory consciousness.

As is evident in the commentaries, we believe that PFT will spur the field to think about the problem of how consciousness arises from nervous function in more theoretically driven and evolutionary-based ways.

\section{R9. Conclusion}

In phylogeny, there has been a trend toward the increased compartmentalization of function (Allman 2000). Having different brain circuits devoted to different kinds of tasks introduces the struggle of parts problem (Mayr 2001), which occurs when the introduction of new structures such as organs involves competitive interactions with extant ones. This problem may have increased the pressure for "many-to-one" solutions, including the conscious field. From our EASE perspective, although such a solution could conceivably occur without something like consciousness, such a possibility was not selected in evolutionary history, in which problems are sometimes solved by counterintuitive and suboptimal strategies (Dawkins 1982; Gould 1977; Mayr 2001; Roe \& Simpson 1958). (We should reiterate that intuitions regarding how sensations should be mapped onto responses are actually computationally impossible [Tsotsos 1995; 2011].)

The commentaries give us confidence that PFT, though based in part on established ideas from diverse fields of study, is a novel synthesis that advances understanding of the role of conscious states in nervous function. PFT attempts to redefine the nature of consciousness. One can propose that, if the heart can be conceptualized as a pump and the kidney as a filter, then consciousness could be conceptualized as a frame composed of tokens (e.g., the color blue, a smell, or pain) that are in a common format, a format that can be sampled only by the action systems of the skeletomotor output system. As an interface of sorts for the action system, the conscious field permits for the response to a given content to be framed by the other contents composing the field. The physical basis of the frame associated with consciousness is most likely unlike anything we currently understand.

\section{ACKNOWLEDGMENTS}

EM: This is dedicated to Robert M. Krauss, my doctoral advisor, who taught me all the important lessons. This research was supported by David Matsumoto and the Center for Human Culture and Behavior at San Francisco State University. We are grateful for the assistance of Jed Katzel, T. Andrew Poehlman, Lawrence Williams, Pat Miller, Ryan Howell, Lucia Jacobs, Allison Allen, Sabrina Bhangal, Hyein Cho, Donish Cushing, Wei Dou, Reza Ghafur, Jessica McMillin, Pooya Razavi, Zaviera Reyes, and Anthony Velasquez.

\section{NOTES}

1. One might argue that smooth muscle actions (e.g., the pupillary reflex) are not veritable forms of action and hence should not be contrasted with voluntary actions, which, to the conscious actor, feel like "real actions." However, it is important to appreciate that, to an intelligent nonhuman observer (e.g., an imaginary, extraterrestrial ethologist), events such as the pupillary reflex would be worthy of being 
"coded" and jotted down as actions on an observation log. To an observer that is agnostic regarding our internal states, the pupillary reflex would appear as action-like as a wink, blink, or the movements of a finger (Skinner, 1953).

2. See neural evidence for this effect in Nath and Beauchamp (2012).

3. Conscious conflicts are often between a high-level system and a low-level system, but they may also be between (a) two low-level systems, as when one is thirsty and must drink painfully cold ice water (Morsella, 2005), or (b) two high-level systems, as in the incongruent condition of the Stroop task.

4. In PFT, conscious contents can be construed as action options, or, more precisely, as constraining dimensions (Morsella \& Bargh 2010), because that which is conscious reduces the space of possible skeletomotor action selection. Unlike with the traditional (circular) definition of conscious representation (which is defined only in terms of being conscious), here the representations are defined by more than their being conscious: They are also defined by their ability to constrain action selection in the skeletomotor output system. These conscious constraining dimensions are not involved in intersensory conflicts, intrasensory conflicts, or the conflicts involving non-skeletal muscle effectors (Morsella et al. 2009a). Akin to a single steering wheel that is controlled by multiple agentic systems, the skeletomotor output system suffers from a particular kind of multi-determined guidance. Just as simple motor acts suffer from the "degrees of freedom" problem, because there are countless ways to instantiate a motor act such as grasping a handle (Rosenbaum 2002), so does action selection, for there are many action options. For action-goal selection, the challenge is met not by unconscious motor algorithms (as in the case of motor programming; Rosenbaum 2002), but by the involvement of the conscious field. In line with this view, Goodale and Milner (2004) conclude that "the primary role of [conscious] perceptual representations is not in the execution of actions, but rather in helping the person or animal arrive at a decision to act in a particular way" (p. 48).

5. Similarly, at the level of operant behavior, skeletomotor considerations are unaffected by, say, incentive states. For example, the actions of navigating through a maze or drawing a candy cane would be carried out in roughly the same manner regardless of the nature of the reward contingencies (Skinner 1953).

6. Supporting the integration consensus, findings in the field of anesthesiology suggest that anesthetic agents work on consciousness in part by halting the integration of information (Alkire et al. 2008; Lee et al. 2009; Mashour 2004; see related evidence in Boveroux et. al. 2010; Långsjö et al. 2012; Lewis et al. 2012; Schroter et al. 2012; Shrouff et al. 2011). Regarding thalamic accounts of consciousness, some anesthetics can cause a reduction in thalamic blood flow and metabolism during the loss of consciousness, whereas other kinds of anesthetics result in increases in thalamic metabolism (e.g., ketamine) or decreases in metabolism while the subject remains conscious (e.g., during sevoflurane sedation; cf. Alkire et al. 2008). Additionally, studies using electroencephalography have shown that as soon as a subject loses consciousness, there is a marked change in cortical electroencephalography, whereas the thalamic electroencephalography remains relatively the same for some minutes afterwards. According to Alkire et al. (2008), this suggests that the thalamus may not be the sole location of consciousness. Investigations into feed-forward and feed-backward connectivity while under anesthesia suggest 
that conscious states are associated with fronto-parietal networks (Lee et al. 2009). (See further discussion on anesthesia and consciousness in Poehlman et al., 2012.)

\section{References}

Ach, N. (1905/1951) Determining tendencies: Awareness. In: Organization and pathology of thought, ed. D. Rapaport, pp. 15-38. Columbia University Press. [rEM]

(Original work published in 1905).

Adrian, E. D. (1942) Olfactory reactions in the brain of the hedgehog. Journal of Physiology 100(4):459-73. [rEM]

Adrian, E. D. (1950a) The electrical activity of the mammalian olfactory bulb. Electroencephalography and Clinical Neurophysiology 2(1):377-88. [rEM]

Adrian, E. D. (1950b) Sensory discrimination: With some recent evidence from the olfactory organ. British Medical Bulletin 6(4):330-32. [rEM]

Alkire, M., Hudetz, A. \& Tononi, G. (2008) Consciousness and anesthesia. Science 322(5903):876-80. [rEM]

Allen, A. K., Wilkins, K., Gazzaley, A. \& Morsella, E. (2013) Conscious thoughts from reflexlike processes: A new experimental paradigm for consciousness research. Consciousness and Cognition 22:1318-31. [rEM]

Allman, J. M. (2000) Evolving brains. Scientific American Library. [rEM]

Allport, D. A. (1989) Visual attention. In: Foundations of cognitive science, vol. 2, ed. M. I. Posner, pp. 631-82. MIT Press. [rEM]

Anderson, J. (1983) The architecture of cognition. Harvard University Press. [rEM]

Aru, J. \& Bachmann, T. (2009) Occipital EEG correlates of conscious awareness when subjective target shine-through and effective visual masking are compared: Bifocal early increase in gamma power and speed-up of P1. Brain Research 1271:60-73. [rEM]

Augustinova, M. \& Ferrand, L. (2014) Automaticity of word reading: Evidence from the semantic Stroop paradigm. Current Directions in Psychological Science 23:343-48. [rEM]

Baars, B. J. (1988) A cognitive theory of consciousness. Cambridge University Press. [rEM]

Baars, B. J. (1997) Some essential differences between consciousness and attention, perception, and working memory. Consciousness and Cognition 6:363-71. [rEM]

Baars, B. J. (2002) The conscious access hypothesis: Origins and recent evidence. Trends in Cognitive Sciences 6:47-52. [rEM] 
Baker, T. B., Piper, M. E., McCarthy, D. E., Majeskie, M. R. \& Fiore, M. C. (2004) Addiction motivation reformulated: An affective processing model of negative reinforcement. Psychological Review 111:33-51. [rEM]

Banks, W. P. (1995) Evidence for consciousness. Consciousness and Cognition 4:270-72. [rEM]

Bar, M., Kassam, K. S., Ghuman, A. S., Boshyan, J., Schmid, A. M., Dale, A. M., Hämäläinen, M. S., Marinkovic, K., Schacter, D. L., Rosen, B. R., \& Halgren, E. (2006) Top-down facilitation of visual recognition. Proceedings of the National Academy of Sciences USA 103:449-54. [rEM]

Bargh, J. A. \& Morsella, E. (2008) The unconscious mind. Perspectives on Psychological Science 3:73-79. [rEM]

Baumeister, R. F. \& Vohs, K. D. (2004) Handbook of self-regulation: Research, theory, and applications. Guilford. [rEM]

Beshel, J., Kopell, N. \& Kay, L. M. (2007) Olfactory bulb gamma oscillations are enhanced with task demands. Journal of Neuroscience 27:8358-65. [rEM]

Bindra, D. (1974) A motivational view of learning, performance, and behavior modification. Psychological Review 81:199-213. [rEM]

Bindra, D. (1978) How adaptive behavior is produced: A perceptual-motivational alternative to response-reinforcement. Behavioral and Brain Sciences 1:41-91. [rEM]

Block, N. (1995) On a confusion about a function of consciousness. Behavioral and Brain Sciences 18:227-87. [rEM]

Block, N. (2007) Consciousness, accessibility, and the mesh between psychology and neuroscience. Behavioral and Brain Sciences 30:481-548. [rEM]

Boveroux, P., Vanhaudenhuyse, A., Bruno, M. A., Noirhomme, Q., Lauwick, S., Luxen, A. \& Degueldre, C., Plenevaux, A., Schnakers, C., Phillips, C., Brichant, J. F., Bonhomme, V., Maquet, P., Greicius, M. D., Laureys, S., \& Boly, M. (2010) Breakdown of within- and between-network resting state functional magnetic resonance imaging connectivity during propofol-induced loss of consciousness. Anesthesiology 113:1038-53. [rEM]

Bruns, A. \& Eckhorn, R. (2004) Task-related coupling from high-to low-frequency signals among visual cortical areas in human subdural recordings. International Journal of Psychophysiology 51(2):97-116. [rEM]

Buzsáki, G. (2006) Rhythms of the brain. Oxford University Press. [rEM]

Carlson, N. R. (1994) Physiology of behavior. Allyn and Bacon. [rEM] 
Cho, H., Zarolia, P., Velasquez, A., \& Morsella, E. (2015). Cognitive- versus emotion-based involuntary cognitions: An informative contrast for the reflexive imagery task. Poster presented at the Annual Convention of the Association for Psychological Science, New York.

Cisek, P. (2007) Cortical mechanisms of action selection: The affordance competition hypothesis. Philosophical Transactions of the Royal Society B 362:1585-99. [rEM]

Cisek, P. \& Kalaska, J. F. (2010) Neural mechanisms for interacting with a world full of action choices. Annual Review of Neuroscience 33:269-98. [rEM]

Clark, A. (2002) Is seeing all it seems? Action, reason and the grand illusion. Journal of Consciousness Studies 9:181-202. [rEM]

Cohen, M. A., Cavanagh, P., Chun, M. M. \& Nakayama, K. (2012) The attentional requirements of consciousness. Trends in Cognitive Sciences 16:411-17. [rEM]

Cooney, J. W. \& Gazzaniga, M. S. (2003) Neurological disorders and the structure of human consciousness. Trends in Cognitive Sciences 7:161-66. [rEM]

Cooper, A. D., Sterling, C. P., Bacon, M. P. \& Bridgeman, B. (2012) Does action affect perception or memory? Vision Research 62:235-40. [rEM]

Corr, P. J. \& Morsella, E. (2015) The conscious control of behavior: Revisiting Gray's comparator model. In: Personality and control, vol. 4, ed. P. J. Corr, M. Fajkowska, M. W. Eysenck \& A. Wytykowska, pp. 15-42. Eliot Werner. [rEM]

Crick, F. \& Koch, C. (1990) Toward a neurobiological theory of consciousness. Seminars in the Neurosciences 2:263-75. [rEM]

Crick, F. \& Koch, C. (2000) The unconscious homunculus. In: Neural correlates of consciousness, ed. T. Metzinger, pp. 103-10. MIT Press. [rEM]

Damasio, A. R., Tranel, D., \& Damasio, H. C. (1991). Somatic markers and the guidance of behavior: Theory and preliminary testing. In H. S. Levin et al. (Eds.), Frontal lobe function and dysfunction (pp. 217-229). London: Oxford University Press. [rEM]

Dawkins, R. (1982) The extended phenotype: The long reach of the gene. Oxford University Press. [rEM]

Dehaene, S. (2014) Consciousness and the brain: Deciphering how the brain codes our thoughts. Viking. [rEM]

Dennett, D. C. (1991) Consciousness explained. Little, Brown. [rEM] 
Desender, K., van Opstal, F. V. \& van den Bussche, E. (2014) Feeling the conflict: The crucial role of conflict experience in adaptation. Psychological Science 25:675-83. [rEM]

Doesburg, S. M., Green, J. L., McDonald, J. J. \& Ward, L. M. (2009) Rhythms of consciousness: Binocular rivalry reveals large-scale oscillatory network dynamics mediating visual perception. PLoS 4:e.0006142. [rEM]

Doesburg, S. M., Kitajo, K. \& Ward, L. M. (2005) Increased gamma-band synchrony precedes switching of conscious perceptual objects in binocular rivalry. NeuroReport 16:1139-42. [rEM]

Eeckman, F. H. \& Freeman, W. J. (1990) Correlations between unit firing and EEG in the rat olfactory system. Brain Research 528(2):238-44. [rEM]

Ehrsson, H. H. (2007) The experimental induction of out-of-body experiences. Science 317(5841):1048. [rEM]

Eimer, M. \& Schlaghecken, F. (2003) Response facilitation and inhibition in subliminal priming. Biological Psychology 64:7-26. [rEM]

Einstein, A. \& Infeld, L. (1938) The evolution of physics. Touchstone. [rEM]

Engel, A. K. \& Singer, W. (2001) Temporal binding and the neural correlates of sensory awareness. Trends in Cognitive Sciences 5:16-25. [rEM]

Eriksen, C. W. \& Schultz, D. W. (1979) Information processing in visual search: A continuous flow conception and experimental results. Perception and Psychophysics 25:249-63. [rEM]

Filevich, E. \& Haggard, P. (2013) Persistence of internal representations of alternative voluntary actions. Frontiers in Psychology 4:202. doi:10.3389/fpsyg.2013.00202. [rEM]

Freeman, W. J. (1975) Mass action in the nervous system: Examination of the neurophysiological basis of adaptive behavior through the EEG. Academic Press. [rEM]

Freeman, W. J. (1979) Nonlinear dynamics of paleocortex manifested in the olfactory EEG. Biological Cybernetics 35(1):21-37. [rEM]

Freeman, W. J. (1987) Nonlinear neural dynamics in olfaction as a model for cognition. In: Dynamics of sensory and cognitive processing in the brain, ed. E. Basar, pp. 19-29. Springer-Verlag. [rEM]

Freeman, W. J. (2004) William James on consciousness, revisited. Chaos and Complexity Letters 1:17-42. [rEM] 
Freeman, W. J. (2007) Indirect biological measures of consciousness from field studies of brains as dynamical systems. Neural Networks 20:1021-31. [rEM]

Fries, P. (2005) A mechanism for cognitive dynamics: Neuronal communication through neuronal coherence. Trends in Cognitive Sciences 9:474-80. [rEM]

Frijda, N. H. (1986) The emotions. Cambridge University Press. [rEM]

Frith, C. D. (2010) What is consciousness for? Pragmatics \& Cognition 18(3):497-551. [rEM]

Glenn, L. L. \& Dement, W. C. (1981) Membrane potential and input resistance of cat spinal motoneurons in wakefulness and sleep. Behavioural Brain Research 2:231-36. [rEM]

Godwin, C. A., Gazzaley, A. \& Morsella, E. (2013) Homing in on the brain mechanisms linked to consciousness: Buffer of the perception-and-action interface. In: The unity of mind, brain and world: Current perspectives on a science of consciousness, ed. A. Pereira Jr. \& D. Lehmann, pp. 43-76. Cambridge University Press. [rEM]

Goodale, M. \& Milner, D. (2004) Sight unseen: An exploration of conscious and unconscious vision. Oxford University Press. [rEM]

Gould, S. J. (1977) Ever since Darwin: Reflections in natural history. Norton. [rEM]

Gray, C. M. \& Skinner, J. E. (1988) Centrifugal regulation of neuronal activity in the olfactory bulb of the waking rabbit as revealed by reversible cryogenic blockade. Experimental Brain Research 69:378-86. [rEM]

Grossberg, S. (1999) The link between brain learning, attention, and consciousness. Consciousness and Cognition 8:1-44. [rEM]

Haidt, J. (2001) The emotional dog and its rational tail: A social intuitionist approach to moral judgment. Psychological Review 108:814-34. [rEM]

Hallett, P. E. (1978) Primary and secondary saccades to goals defined by instructions. Vision Research 18:1279-96. [rEM]

Hameroff, S. (2010) The "conscious pilot" - dendritic synchrony moves through the brain to mediate consciousness. Journal of Biological Physics 36:71-93. [rEM]

Harleß, E. (1861) Der Apparat des Willens [The apparatus of the will]. Zeitshrift für Philosophie und philosophische Kritik 38:499-507. [rEM]

Helmholtz, H. v. (1856/1961) Treatise of physiological optics: Concerning the perceptions in general. In: Classics in psychology, ed. T. Shipley, pp. 79-127. Philosophy Library. (Original work published in 1856) [rEM] 
Herz, R. S. (2003). The effect of verbal context on olfactory perception. Journal of Experimental Psychology: General, 132, 595 - 606.

Hochberg, J. (1998) Gestalt theory and its legacy: Organization in eye and brain, in attention and mental representation. In: Perception and cognition at century's end: Handbook of perception and cognition, 2nd edition, ed. J. Hochberg, pp. 253-306. Academic Press. [rEM]

Hommel, B. (2013) Dancing in the dark: No role for consciousness in action control. Frontiers in Psychology 4:380. doi:10.3389/fpsyg.2013.00380. [rEM]

Hong, L. E., Buchanan, R. W., Thaker, G. K., Shepard, P. D. \& Summerfelt, A. (2008) Beta ( 16 $\mathrm{Hz}$ ) frequency neural oscillations mediate auditory sensory gating in humans. Psychophysiology 45(2):197-204. [rEM]

Hughes, G., Velmans, M. \& de Fockert, J. (2009) Unconscious priming of a no-go response. Psychophysiology 46:1258-69. [rEM]

Hummel, F. \& Gerloff, C. (2005) Larger interregional synchrony is associated with greater behavioral success in a complex sensory integration task in humans. Cerebral Cortex 15:670-78. [rEM]

Jackendoff, R. S. (1990) Consciousness and the computational mind. MIT Press. [rEM]

Jackson, F. (1986) What Mary didn’t know. Journal of Philosophy 83:291-95. [rEM]

James, W. (1890) The principles of psychology. Dover. [rEM]

Jeannerod, M. (2006). Motor cognition: What action tells the self. New York: Oxford University Press.

Jung-Beeman, M., Bowden, E. M., Haberman, J., Frymiare, J. L., Arambel-Liu, S., Greenblatt, R., Reber, P. J. \& Kounios, J. (2004) Neural activity when people solve verbal problems with insight. PLoS Biology 2:500-10. [rEM]

Kaufman, M. T., Churchland, M. M., Ryu, S. I. \& Shenoy, K. V. (2015) Vacillation, indecision and hesitation in moment-by-moment decoding of monkey cortex. eLife 4:e04677. doi:10.7554/eLife.04677. [rEM]

Kay, L. M. \& Beshel, J. (2010) A beta oscillation network in the rat olfactory system during a 2alternative choice odor discrimination task. Journal of Neurophysiology 104:829-39. [rEM]

Kay, L. M., Beshel, J., Brea, J., Martin, C., Rojas-L'bano, D. \& Kopell, N. (2009) Olfactory oscillations: The what, how and what for. Trends in Neurosciences 32:207-14. [rEM] 
Kim, S., Singer, B. H. \& Zochowski, M. (2006) Changing roles for temporal representation of odorant during the oscillatory response of the olfactory bulb. Neural Computation 18(4):794-816. [rEM]

Kinsbourne, M. (1996) What qualifies a representation for a role in consciousness? In: Scientific approaches to consciousness, ed. J. D. Cohen \& J. W. Schooler, pp. 335-55. Erlbaum. [rEM]

Kinsbourne, M. (2000) How is consciousness expressed in the cerebral activation manifold? Brain and Mind 2:265-74. [rEM]

Koch, C. (2004) The quest for consciousness: A neurobiological approach. Roberts. [rEM]

Koch, C. (2014) Consciousness. Colloquium delivered at the Redwood Center for Theoretical Neuroscience, December 2, 2014. University of California, Berkeley. [rEM]

Koch, C. \& Tsuchiya, N. (2007) Attention and consciousness: Two distinct brain processes. Trends in Cognitive Sciences 11:16-22. [rEM]

Krauzlis, R. J., Bollimunta, A., Arcizet, F. \& Wang, L. (2014) Attention as an effect not a cause. Trends in Cognitive Sciences 18:457-64. [rEM]

Långsjö, J. W., Alkire, M. T., Kaskinoro, K., Hayama, H., Maksimow, A., Kaisti, K. K., Aalto, S., Aantaa, R., Jääskeläinen, S. K., Revonsuo, A. \& Scheinin, H. (2012) Returning from oblivion: Imaging the neural core of consciousness. Journal of Neuroscience 32:4935-43. [rEM]

Lashley, K. S. (1956) Cerebral organization and behavior. Proceedings of the Association for Research in Nervous and Mental Diseases 36:1-18. [rEM]

Laurent, G. \& Davidowitz, H. (1994) Encoding of olfactory information with oscillating neural assemblies. Science 265(5180):1872-75. [rEM]

LeDoux, J. (2012) Rethinking the emotional brain. Neuron 73:653-76. [rEM]

LeDoux, J. E. (1996) The emotional brain: The mysterious underpinnings of emotional life. Simon and Schuster. [rEM]

LeDoux, J. E. (2000) Emotion circuits in the brain. Annual Review of Neuroscience 23:155-84. [rEM]

Lee, U., Kim, S., Noh, G. J., Choi, B. M., Hwang, E. \& Mashour, G. (2009) The directionality and functional organization of frontoparietal connectivity during consciousness and anesthesia in humans. Consciousness and Cognition 18:1069-78. [rEM]

Levelt, W. J. M. (1989) Speaking: From intention to articulation. MIT Press. [rEM] 
Lewis, L. D., Weiner, V. S., Mukamel, E. A., Donoghue, J. A., Eskandar, E. N., Madsen, J. R. \& Purdon, P. L. (2012) Rapid fragmentation of neuronal networks at the onset of propofolinduced unconsciousness. Proceedings of the National Academy of Sciences USA 109(49):E3377-86. [rEM]

Livnat, A. \& Pippenger, N. (2006) An optimal brain can be composed of conflicting agents. Proceedings of the National Academy of Sciences USA 103:3198-202. [rEM]

Loewenstein, G. (1996) Out of control: visceral influences on behavior. Organizational Behavior and Human Decision Processes 65:272-92. [rEM]

Logan, G. D., Taylor, S. E. \& Etherton, J. L. (1999) Attention and automaticity: Toward a theoretical integration. Psychological Research 62:165-81. [rEM]

Logan, G. D., Yamaguchi, M., Schall, J. D. \& Palmeri, T. J. (2015) Inhibitory control in mind and brain 2.0: Blocked input models of saccadic countermanding. Psychological Review 122:115-47. [rEM]

Logothetis, N. K. \& Schall, J. D. (1989) Neuronal correlates of subjective visual perception. Science 245:761-62. [rEM]

Lorenz, K. (1963) On aggression. Harcourt, Brace, \& World. [rEM]

MacLeod C. M., \& MacDonald P. A. (2000). Interdimensional interference in the Stroop effect: uncovering the cognitive and neural anatomy of attention. Trends in Cognitive Sciences, 4, $383-391$.

Macphail, E. M. (1998) The evolution of consciousness. Oxford University Press. [rEM]

Mainland, J. D. \& Sobel, N. (2006) The sniff is part of the olfactory percept. Chemical Senses 31:181-96. [rEM]

Marcel, A. J. (1993) Slippage in the unity of consciousness. In: Experimental and theoretical studies of consciousness. Ciba Foundation Symposium 174, ed. G. R. Bock \& J. Marsh, pp. 168-80. Wiley. [rEM]

Marr, D. (1982) Vision: A computational investigation into the human representation and processing of visual information. W. H. Freeman. [rEM]

Martin, C., Beshel, J. \& Kay, L. M. (2007) An olfacto-hippocampal network is dynamically involved in odor-discrimination learning. Journal of Neurophysiology 98(4):2196-205. [rEM]

Mashour, G. A. (2004) Consciousness unbound: Toward a paradigm of general anesthesia. Anesthesiology 100:428-33. [rEM] 
Masicampo, E. J. \& Baumeister, R. F. (2013) Conscious thought does not guide moment-tomoment actions-it serves social and cultural functions. Frontiers in Psycholology 4:478. doi:10.3389/fpsyg.2013.00478. [rEM]

Mayr, E. (2001) What evolution is. Weidenfeld \& Nicolson. [rEM]

McClelland, J. L. (1979) On the time-relations of mental processes: An examination of systems of processes in cascade. Psychological Review 86:287-330. [rEM]

Meador, K. J., Ray, P. G., Echauz, J. R., Loring, D. W. \& Vachtsevanos, G. J. (2002) Gamma coherence and conscious perception. Neurology 59:847-54. [rEM]

Melzack, R. \& Casey, K. L. (1968) Sensory, motivational, and central control determinants of pain: A new conceptual model. In: The skin senses, ed. D. R. Kenshalo. Charles C. Thomas. [rEM]

Merker, B. (2007) Consciousness without a cerebral cortex: A challenge for neuroscience and medicine. Behavioral and Brain Sciences 30:63-134. [rEM]

Merker, B. (2012) From probabilities to percepts: A subcortical "global best estimate buffer" as locus of phenomenal experience. In: Being in time: Dynamical models of phenomenal experience, ed. S. Edelman, T. Fekete \& N. Zach, pp. 37-80. John Benjamins. [rEM]

Merker, B. (2013) The efference cascade, consciousness, and its self: Naturalizing the first person pivot of action control. Frontiers in Psycholology 4:1-20.

doi:10.3389/fpsyg.2013.00501. [rEM]

Merrick, C., Farnia, M., Jantz, T. K., Gazzaley, A. \& Morsella, E. (2015) External control of the stream of consciousness: Stimulus-based effects on involuntary thought sequences. Consciousness and Cognition 33:217-225. [rEM]

Merrick, C., Godwin, C. A., Geisler, M. W. \& Morsella, E. (2014) The olfactory system as the gateway to the neural correlates of consciousness. Frontiers in Psychology 4:1011. doi:10.3389/fpsyg.2013.01011. [rEM]

Miller, N. E. (1959) Liberalization of basic S-R concepts: Extensions to conflict behavior, motivation, and social learning. In: Psychology: A study of science, vol. 2, ed. S. Koch, pp. 196-292. McGraw-Hill. [rEM]

Minsky, M. (1985) The society of mind. Simon and Schuster. [rEM]

Molapour, T., Berger, C. C., \& Morsella, E. (2011). Did I read or did I name? Diminished awareness of processes yielding identical 'outputs.' Consciousness and Cognition, 20, $1776-1780$. 
Morsella, E. (2005) The function of phenomenal states: Supramodular interaction theory. Psychological Review 112:1000-21. [rEM]

Morsella, E. \& Bargh, J. A. (2010) What is an output? Psychological Inquiry 21:354-70. [rEM]

Morsella, E. \& Bargh, J. A. (2011) Unconscious action tendencies: Sources of "un-integrated" action. In: The handbook of social neuroscience, ed. J. T. Cacioppo \& J. Decety, pp. 335-47. Oxford University Press. [rEM]

Morsella, E., Berger, C. C. \& Krieger, S. C. (2011) Cognitive and neural components of the phenomenology of agency. Neurocase 17:209-30. [rEM]

Morsella, E., Gray, J. R., Krieger, S. C. \& Bargh, J. A. (2009a) The essence of conscious conflict: Subjective effects of sustaining incompatible intentions. Emotion 9:717-28. [rEM]

Morsella, E., Wilson, L. E., Berger, C. C., Honhongva, M., Gazzaley, A. \& Bargh, J. A. (2009b) Subjective aspects of cognitive control at different stages of processing. Attention, Perception \& Psychophysics 71:1807-24. [rEM]

Morsella, E., Zarolia, P. \& Gazzaley, A. (2012) Cognitive conflict and consciousness. In: Cognitive consistency: A unifying concept in social psychology, ed. B. Gawronski \& F. Strack, pp. 19-46. Guilford Press. [rEM]

Mudrik, L., Faivre, N. \& Koch, C. (2014) Information integration without awareness. Trends in Cognitive Sciences 18:488-96. [rEM]

Munakata, Y., Herd, S. A., Chatham, C. H., Depue, B. E., Banich, M. T. \& O'Reilly, R. C. (2011) A unified framework for inhibitory control. Trends in Cognitive Sciences 15:45359. [rEM]

Nagasako, E. M., Oaklander, A. L. \& Dworkin, R. H. (2003) Congenital insensitivity to pain: An update. Pain 101:213-19. [rEM]

Nagel, T. (1974) What is it like to be a bat? Philosophical Review 83:435-50. [rEM]

Nath, A. R. \& Beauchamp, M. S. (2012) A neural basis for interindividual differences in the McGurk effect, a multisensory speech illusion. NeuroImage 59:781-87. [rEM]

Neumann, O. (1987) Beyond capacity: A functional view of attention. In: Perspectives on perception and action, ed. H. Heuer \& A. F. Sanders, pp. 361-94. Erlbaum. [rEM]

Neville, K. R. \& Haberly, L. B. (2003) Beta and gamma oscillations in the olfactory system of the urethane-anesthetized rat. Journal of Neurophysiology 90(6):3921-30. [rEM] 
Nisbett, R. E. \& Wilson, T. D. (1977) Telling more than we can know: Verbal reports on mental processes. Psychological Review 84:231-59. [rEM]

Oberauer, K. \& Hein, L. (2012) Attention to information in working memory. Current Directions in Psychological Science 21:164-69. [rEM]

Öhman, A. \& Mineka, S. (2001) Fears, phobias, and preparedness: Toward an evolved module of fear and fear learning. Psychological Review 108:483-522. [rEM]

Olsson, A. \& Phelps, E. A. (2004) Learned fear of "unseen" faces after Pavlovian, observational, and instructed fear. Psychological Science 15:822-28. [rEM]

Panagiotaropolous, T. I., Deco, G., Kapoor, V. \& Logothetis, N. K. (2012) Neuronal discharges and gamma oscillations explicitly reflect visual consciousness in the lateral prefrontal cortex. Neuron 74:924-35. [rEM]

Pashler, H. (1993) Doing two things at the same time. American Scientist 81:48-55. [rEM]

Passingham, R. (1995) The frontal lobes and voluntary action. Oxford University Press. [rEM]

Pinker, S. (1997) How the mind works. Norton. [rEM]

Poehlman, T. A., Jantz, T. K. \& Morsella, E. (2012) Adaptive skeletal muscle action requires anticipation and "conscious broadcasting." Frontiers in Psychology 3:369. [rEM]

Poellinger, A., Thomas, R., Lio, P., Lee, A., Makris, N., Rosen, B. R. \& Kwong, K. K. (2001) Activation and habituation in olfaction-an fMRI study. Neuroimage 13(4):547-60. [rEM]

Preston, J. \& Wegner, D. M. (2009) Elbow grease: The experience of effort in action. In: Oxford handbook of human action, ed. E. Morsella, J. A. Bargh \& P. M. Gollwitzer, pp. 469-86. Oxford University Press. [rEM]

Prinz, J. (2007) The intermediate level theory of consciousness. In: The Blackwell companion to consciousness, ed. M. Velmans \& S. Schneider, pp. 248-60. Blackwell. [rEM]

Prinz, W. (2003) How do we know about our own actions? In: Voluntary action: Brains, minds, and sociality, ed. S. Maasen, W. Prinz \& G. Roth, pp. 21-33. Oxford University Press. [rEM]

Prinz, W. (2012) Open minds: The social making of agency and intentionality. MIT Press. [rEM]

Puttemans, V., Wenderoth, N. \& Swinnen, S. P. (2005) Changes in brain activation during the acquisition of a multifrequency bimanual coordination task: From the cognitive stage to advanced levels of automaticity. Journal of Neuroscience 25:4270-78. [rEM] 
Ramachandran, V. S. (1999) Phantoms in the brain: Probing the mysteries of the human mind. Harper Perennial. [rEM]

Riddle, T. A., Rosen, H. J. \& Morsella, E. (2015) Is that me? Sense of agency as a function of intra-psychic conflict. Journal of Mind and Behavior 36:27-46. [rEM]

Roe, A. \& Simpson, G. G. (1958) Behavior and evolution. Yale University Press. [rEM]

Rosenbaum, D. A. (2002) Motor control. In: Stevens' handbook of experimental psychology: Vol. 1. Sensation and perception, 3rd edition, ed. H. Pashler (series ed.) \& S. Yantis (vol. ed.), pp. 315-39. Wiley. [rEM]

Roser, M. \& Gazzaniga, M. S. (2004) Automatic brains-interpretive minds. Current Directions in Psychological Science 13:56-59. [rEM]

Sauseng, P. \& Klimesch, W. (2008) What does phase information of oscillatory brain activity tell us about cognitive processes? Neuroscience \& Biobehavioral Reviews 32(5):1001-13. [rEM]

Schlaghecken, F., Bowman, H. \& Eimer, M. (2006) Dissociating local and global levels of perceptuo-motor control in masked priming. Journal of Experimental Psychology: Human Perception and Performance 32:618-32. [rEM]

Schroter, M., Spoormaker, V., Schorer, A., Wohlschlager, A., Czish, M., Kochs, E. \& Zimmer, C., Hemmer, B., Schneider, G., Jordan, D. \& Ilg, R. (2012) Spatiotemporal reconfiguration of large-scale brain functional networks during propofol-induced loss of consciousness. Journal of Neuroscience 32:12832-40. [rEM]

Schrouff, J., Perlbarg, V., Boly, M., Marrelec, G., Boveroux, P., Vanhaudenhuyse, A., Bruno, M. A., Laureys, S., Phillips, C., Pélégrini-Isaac, M., Maquet, P. \& Benali, H., (2011) Brain functional integration decreases during propofol-induced loss of consciousness. NeuroImage 57:198-205. [rEM]

Searle, J. R. (2000) Consciousness. Annual Review of Neurosciences 23:557-78. [rEM]

Selfridge, O. G. (1959) Pandemonium: A paradigm for learning. In: Mechanization of thought processes: Proceedings of a symposium held at the National Physics Laboratory on 24th, 25th, 25th and 27th November 1958, vol. 1, pp. 511-26. Her Majesty's Stationary Office. [rEM]

Sergent, C. \& Dahaene, S. (2004) Is consciousness a gradual phenomenon? Evidence for an allor-none bifurcation during the attentional blink. Psychological Science 15:720-28. [rEM]

Shallice, T. (1972) Dual functions of consciousness. Psychological Review 79:383-93. [rEM] 
Shepherd, G. M. (2006) Smell images and the flavour system in the human brain. Nature 444(7117):316-21. [rEM]

Shepherd, G. M. (2007) Perspectives on olfactory processing, conscious perception, and orbitofrontal cortex. Annals of the New York Academy of Sciences 1121:87-101. [rEM]

Siegel, M., Donner, T. H. \& Engel, A. K. (2012) Spectral fingerprints of large-scale neuronal interactions. Nature Reviews Neuroscience 13:121-34. [rEM]

Simons, D. J. \& Levin, D. T. (1997) Change blindness. Trends in Cognitive Sciences 1:261-67. $[\mathrm{rEM}]$

Simpson, G. G. (1949) The meaning of evolution. Yale University Press. [rEM]

Singer, W. (2011) Consciousness and neuronal synchronization. In: The neurology of consciousness, ed. S. Laureys \& G. Tononi, pp. 43-52. Academic Press. [rEM]

Skinner, B. F. (1953) Science and human behavior. Macmillan. [rEM]

Sobel, N., Prabhakaran, V., Zhao, Z., Desmond, J. E., Glover, G. H., Sullivan, E. V. \& Gabrieli, J. D. (2000) Time course of odorant-induced activation in the human primary olfactory cortex. Journal of Neurophysiology 83(1):537-51. [rEM]

Sperry, R. W. (1952) Neurology and the mind-brain problem. American Scientist 40:291-312. $[\mathrm{rEM}]$

Stevenson, R. J. (2009). Phenomenal and access consciousness in olfaction. Consciousness and Cognition, 18, 1004 - 1017.

Stopfer, M., Bhagavan, S., Smith, B. H. \& Laurent, G. (1997) Impaired odour discrimination on desynchronization of odour-encoding neural assemblies. Nature 390(6655):70-74. [rEM]

Suhler, C. L. \& Churchland, P. S. (2009) Control: Conscious and otherwise. Trends in Cognitive Sciences 13:341-47. [rEM]

Tetlock, P. E. (2002) Social functionalist frameworks for judgment and choice: Intuitive politicians, theologians, and prosecutors. Psychological Review 109:451-71. [rEM]

Thagard, P. \& Stewart, T. C. (2014) Two theories of consciousness: Semantic pointer competition vs. information integration. Consciousness and Cognition 30:73-90. [rEM]

Thorndike, E. L. (1905) The functions of mental states. In: The elements of psychology, ed. E. L. Thorndike, pp. 111-19. A. G. Seiler. [rEM] 
Tipper, S. P. (1985) The negative priming effect: Inhibitory priming by ignored objects. The Quarterly Journal of Experimental Psychology 37A:571-90. [rEM]

Tolman, E. C. (1948) Cognitive maps in rats and men. Psychological Review 55:189-208. $[\mathrm{rEM}]$

Tsotsos, J. K. (1995) Behaviorist intelligence and the scaling problem. Artificial Intelligence 75:135-60. [rEM]

Tsotsos, J. K. (2011) A computational perspective on visual attention. MIT Press. [rEM]

Uhlhaas, P. J., Pipa, G., Lima, B., Melloni, L., Neuenschwander, S., Nikolic, D. \& Singer, W. (2009) Neural synchrony in cortical networks: History, concept and current status. Frontiers in Integrative Neuroscience 3:17. doi:10.3389/neuro.07.017.2009. [rEM]

Vanderwolf, C. H. \& Zibrowski, E. M. (2001) Pyriform cortex beta-waves: Odor-specific sensitization following repeated olfactory stimulation. Brain Research 892:301-308. [rEM]

Van Opstal, F., Gevers, W., Osman, M. \& Verguts, T. (2010) Unconscious task application. Consciousness \& Cognition 19:999-1006. [rEM]

Woodman, G. F., \& Vogel, E. K. (2005). Fractionating working memory: Consolidation and maintenance are independent. Psychological Science, 16, 106-113.

von Stein, A. \& Sarnthein, J. (2000) Different frequencies for different scales of cortical integration: From local gamma to long range alpha/theta synchronization. International Journal of Psychophysiology 38(3):301-13. [rEM]

Ward, L. M. (2003) Synchronous neural oscillations and cognitive processes. Trends in Cognitive Sciences 7:553-59. [rEM]

Welford, A. T. (1952) The "psychological refractory period" and the timing of high-speed performance: A review and a theory. British Journal of Psychology 43:2-19. [rEM]

Werner, H. \& Kaplan, B. (1963) Symbol formation. Wiley. [rEM]

Wessel, J. R., Haider, H., \& Rose, M. (2012). The transition from implicit to explicit representations in incidental learning situations: More evidence from high-frequency EEG coupling. Experimental Brain Research, 217, 153 - 162.

Wilke, M., Mueller, K.-M. \& Leopold, D. A. (2009) Neural activity in the visual thalamus reflects perceptual suppression. Proceedings of the National Academy of Sciences USA 106:9465-70. [rEM]

Wundt, W. (1900) Die sprache. Engelmann. [rEM] 
Wundt, W. (1902/1904) Principles of physiological psychology. Translated from the 5th German edition (1904) by E. B. Titchener. Swan Sonnenschein. (Original work published in 1902) [rEM]

Xu, F., Greer, C. A. \& Shepherd, G. M. (2000) Odor maps in the olfactory bulb. Journal of Comparative Neurology 422(4):489-95. [rEM]

Zibrowski, E. M. \& Vanderwolf, C. H. (1997) Oscillatory fast wave activity in the rat pyriform cortex: relations to olfaction and behavior. Brain Research 766:39-49. [rEM] 